\title{
Eosinophilic esophagitis: Updated consensus recommendations for children and adults
}

Chris A. Liacouras, MD, Glenn T. Furuta, MD, Ikuo Hirano, MD, Dan Atkins, MD, Stephen E. Attwood, MD, FRCS, FRCSI, MCh, Peter A. Bonis, MD, A. Wesley Burks, MD, Mirna Chehade, MD, Margaret H. Collins, MD, Evan S. Dellon, MD, MPH, Ranjan Dohil, MD, Gary W. Falk, MD, MS, Nirmala Gonsalves, MD, Sandeep K. Gupta, MD, David A. Katzka, MD, Alfredo J. Lucendo, MD, PhD, Jonathan E. Markowitz, MD, MSCE, Richard J. Noel, MD, Robert D. Odze, MD, FRCP, Philip E. Putnam, MD, FAAP, Joel E. Richter, MD, FACP, MACG, Yvonne Romero, MD, Eduardo Ruchelli, MD, Hugh A. Sampson, MD, Alain Schoepfer, MD, Nicholas J. Shaheen, MD, MPH, Scott H. Sicherer, MD, Stuart Spechler, MD, Jonathan M. Spergel, MD, PhD, Alex Straumann, MD, Barry K. Wershil, MD, Marc E. Rothenberg, MD, PhD,* and Seema S. Aceves, MD, PhD* 
Eosinophilic esophagitis (EoE) is a clinicopathologic condition of increasing recognition and prevalence. In 2007, a consensus recommendation provided clinical and histopathologic guidance for the diagnosis and treatment of EoE; however, only a minority of physicians use the $\mathbf{2 0 0 7}$ guidelines, which require fulfillment of both histologic and clinical features. Since 2007, the number of EoE publications has doubled, providing new disease insight. Accordingly, a panel of 33 physicians with expertise in pediatric and adult allergy/immunology, gastroenterology, and pathology conducted a systematic review of the EoE literature (since September 2006) using electronic databases. Based on the literature review and expertise of the panel, information and recommendations were provided in each of the following areas of EoE: diagnostics, genetics, allergy testing, therapeutics, and disease complications. Because accumulating animal and human data have provided evidence that EoE appears to be an antigen-driven immunologic process that involves multiple pathogenic pathways, a new conceptual definition is proposed highlighting that EoE represents a chronic, immune/antigen-mediated disease characterized clinically by symptoms related to esophageal dysfunction and histologically by eosinophil-predominant inflammation. The diagnostic guidelines continue to define $\mathrm{EoE}$ as an isolated chronic disorder of the esophagus diagnosed by the need of both clinical and pathologic features. Patients commonly have high rates of concurrent allergic diatheses, especially food sensitization, compared with the general population. Proved therapeutic options include chronic dietary elimination, topical corticosteroids, and esophageal dilation. Important additions since 2007 include genetic underpinnings that implicate EoE susceptibility caused by polymorphisms in the thymic stromal lymphopoietin protein gene and the description of a new potential disease phenotype, proton pump inhibitor-responsive esophageal eosinophila. Further advances and controversies regarding diagnostic methods, surrogate disease markers, allergy testing, and treatment approaches are discussed. (J Allergy Clin Immunol 2011;128:3-20.)

Key words: Eosinophils, eosinophilic, esophagitis, esophageal, food allergy

Discuss this article on the JACI Journal Club blog: www. jaci-online.blogspot.com.

Since the publication of the eosinophilic esophagitis (EoE) consensus recommendation (CR) in 2007, ${ }^{1}$ scientific publications focusing on EoE have nearly doubled, and the recognition of patients who have eosinophil-predominant esophagitis has increased dramatically. Early studies described aspects of the condition in children, but it has become clear that adults have a similar

\footnotetext{
Complete information for the authors, including affiliations and study responsibilities, is shown in Appendix E1 in this article's Online Repository at www.jacionline.org.

*These authors contributed equally to this work.

Received for publication February 12, 2011; accepted for publication February 17, 2011. Available online April 7, 2011.

Reprint requests: Chris A. Liacouras, MD, Exton Specialty Center, The Children's Hospital of Philadelphia, 481 John Young Way, Exton, PA 19341. E-mail: liacouras@ email.chop.edu. 0091-6749/\$36.00

(c) 2011 American Academy of Allergy, Asthma \& Immunology doi:10.1016/j.jaci.2011.02.040
}
Abbreviations used
APT: Atopy patch test
$\mathrm{CR}$ : Consensus recommendation
EoE: Eosinophilic esophagitis
GERD: Gastroesophageal reflux disease
hpf: High-power field
PPI: Proton pump inhibitor
SPT: Skin prick test
TSLP: Thymic stromal lymphopoietin

disorder. Practice patterns in multiple subspecialties (adult and pediatric gastroenterology, allergy/immunology, pulmonary medicine, and otolaryngology) have begun to include $\mathrm{EoE}$ in the differential diagnosis of various clinical presentations. Increased recognition, along with the chronic nature of EoE, has led to a steady increase in prevalence.

A salient aspect of the $2007 \mathrm{CR}$ was that EoE was defined as a clinicopathologic entity in which esophageal eosinophilia was a necessary but not sufficient criterion for diagnosis. Most recent publications pertaining to EoE, however, have included cohorts of patients in whom the diagnosis was based solely on the histologic finding of esophageal eosinophilia. In fact, a recent study and a 2010 survey of 1836 physician members of the American College of Gastroenterology, the American Academy of Allergy, Asthma \& Immunology, and the North American Society of Pediatric Gastroenterology, Hepatology, and Nutrition identified that only one third of respondents used the CR definition. ${ }^{2,3}$ Furthermore, the 2007 CR statements regarding the clinical presentation, pathogenesis, treatment, and complications have elucidated ambiguities and controversy in the context of expanding clinical experience and increased scientific investigation.

To address these concerns, an interdisciplinary expert panel was convened with the following goals: (1) to provide clarity to the definition, nomenclature, clinical presentation, histology, and diagnostic testing; (2) to report on various disease phenotypes that might exist; (3) to evaluate allergic manifestations and allergy tests related to antigenic causes of the disease; (4) to review, reassess, and provide recommendations on dietary and medical treatments; and (5) to review the use of esophageal dilation and complications associated with EoE. The interdisciplinary panel subsequently generated this report with the hope that the following information will provide a framework to improve care and develop future studies on EoE.

\section{METHODOLOGY}

A task force of 33 physicians with recognized expertise in the clinical evaluation, endoscopy, histopathology, genetics, allergy, and treatment of EoE was gathered to address specific clinically relevant topics. The expert panel consisted of pediatric and adult gastroenterologists, allergists, and pathologists. A systematic review of the English-language medical literature between September 2006 and August 2010 was performed by using electronic databases (MEDLINE, PubMed, and Ovid). Relevant data were discussed among committee members in a series of conference calls. Critical evaluations included study design, numbers of patients, definitions used, outcomes reported, and potential biases. The chair of each committee synthesized the 
data, and inconsistencies were resolved by means of discussion until a consensus was achieved. The recommendations of each committee included a review and update of the 2007 Consensus Report, clinical recommendations, and proposals for future research. The manuscript was reviewed and approved by all 33 participants.

\section{REVIEW OF 2007 CR AND GUIDELINES}

The original 2007 consensus definition of EoE, based on both a threshold number of eosinophils and clinical parameters of upper intestinal symptoms for which gastroesophageal reflux disease (GERD) was not the underlying cause, might have been problematic. First, the histologic finding of 15 or more eosinophils per high-power field (hpf) in an esophageal biopsy specimen carries no proved biological significance or power to discriminate among various esophageal diseases. Second, the exhortation to eliminate GERD as a potential cause of esophageal eosinophilia (as determined by best clinical practice, which can include either failure of proton pump inhibitors [PPIs] to resolve symptoms and ongoing eosinophilia or a normal $\mathrm{pH}$ impedance monitoring study) has not been rigorously applied or validated.

The reasons for this are multiple and relate, in part, to the identification of at least 2 groups of patients with eosinophilpredominant esophageal inflammation. One group, best described as having GERD with more eosinophils than usual, has abnormal $\mathrm{pH}$ monitoring results and a clinicopathologic response to PPIs. ${ }^{4,5}$ Another group, best described as having PPI-responsive esophageal eosinophilia, has normal $\mathrm{pH}$ study results but nevertheless shows a clinicopathologic response to proton pump inhibition. ${ }^{6}$ Whether this latter group represents GERD that was not identified by means of $\mathrm{pH}$ impedance-monitoring studies* or a clinical response to the potential anti-inflammatory properties of PPIs is not yet certain. In neither of these groups has an association with an antigenic or immunologic cause of esophageal eosinophilia been thoroughly studied.

Another inherent problem was the use of the abbreviation "EE." Although easily understood by allergists and pathologists, among gastroenterologists EE classically defines "erosive esophagitis." The use of the abbreviation EoE rather than EE for EoE should eliminate the potential for this confusion.

No studies have been published since the CR that would clearly permit diagnosis or phenotype discrimination based on pathognomonic clinical/histologic features or biomarkers. Thus although many studies performed since 2007 have used the 2007 CR as proposed, the majority do not, leaving diagnostic uncertainty both for patients and within the published literature. ${ }^{7}$ Because of the increasing recognition of patients with esophageal eosinophilia and the clinical demand for a more relevant diagnostic guideline, an urgent need has developed to revise the previously published $\mathrm{CR} .{ }^{8-10}$

\footnotetext{
*pH testing can be done with a transnasal tube with a $\mathrm{pH}$ sensor at its tip, where the tip is placed $5 \mathrm{~cm}$ above the manometrically determined proximal border of the lower esophageal sphincter, or can be done with a wireless $\mathrm{pH}$ capsule that is pinned $6 \mathrm{~cm}$ above the squamocolumnar junction at endoscopy. Both systems capture $\mathrm{pH}$ recordings to measure the percentage of total time that an acidic $\mathrm{pH}(<4.0)$ is present in the distal esophagus, along with other measurements. Recorders have patient-activated buttons to indicate symptoms, meals, and posture (upright or supine). Thus these devices can be used to measure the temporal relation between the patients' recorded symptoms and acid reflux. Complimenting $\mathrm{pH}$ technology is the advent of impedance. Impedance monitors act like motion detectors and show the direction of flow not only of acidic liquids, but also of gas, and liquid of any $\mathrm{pH}$ (weakly acidic, neutral, or basic).
}

TABLE I. Diseases associated with esophageal eosinophilia

\section{GERD}

EoE

Eosinophilic gastrointestinal diseases

Celiac disease

Crohn disease

Infection

Hypereosinophilic syndrome

Achalasia

Drug hypersensitivity

Vasculitis

Pemphigoid vegetans

Connective tissue disease

Graft-versus-host disease

\section{CONCEPTUAL DEFINITION AND DIAGNOSTIC GUIDELINES FOR EoE \\ Proposed conceptual definition of EoE}

Recognition of the differences between esophageal eosinophilia as a histologic descriptor and EoE as a disease, in itself, is critical (Table I). As clinical experience has developed and as more patients are being identified, varying phenotypes based on symptoms or anatomic abnormalities (eg, stricturing) might define a "spectrum" of EoE. As supported by a number of past and recent basic/translational studies and clinical experience demonstrating that the underlying cause of EoE is likely an aberrant "immune" or "antigenic" response associated with consistent endoscopic, histologic, and genetic abnormalities, a conceptual definition for EoE is proposed. ${ }^{11-45}$ Use of this conceptual definition not only will provide a framework to refine our perceptions and hypotheses but also will guide future diagnostic tests, therapeutic modalities, and pathogenetic studies on EoE.

\section{Conceptual definition}

Eosinophilic esophagitis represents a chronic, immune/ antigen-mediated esophageal disease characterized clinically by symptoms related to esophageal dysfunction and histologically by eosinophil-predominant inflammation.

\section{Proposed diagnostic guideline for EoE}

In conjunction with this conceptual definition of EoE, recent clinical experience and research supports revisions in the original diagnostic guidelines for EoE. Rationales for statements in the current guidelines compared with the $2007 \mathrm{CR}$ are listed in Table II.

\section{Diagnostic guideline}

EoE is a clinicopathologic disease. Clinically, EoE is characterized by symptoms related to esophageal dysfunction. Pathologically, 1 or more biopsy specimens must show eosinophil-predominant inflammation. With few exceptions, 15 eosinophils/hpf (peak value) is considered a minimum threshold for a diagnosis of EoE. The disease is isolated to the esophagus, and other causes of esophageal eosinophilia should be excluded, specifically PPI-responsive esophageal eosinophilia. The disease should remit with treatments of dietary exclusion, topical corticosteroids, or both. EoE should be diagnosed by clinicians, taking into consideration all clinical and pathologic information; neither of these parameters should be interpreted in isolation. 
1. Change in EE abbreviation. EE often has been used as an abbreviation for erosive esophagitis. Use of the abbreviation EoE rather than EE for eosinophilic esophagitis should eliminate the potential for confusion.

2. Inclusion of the word chronic. Clinical experience supports that EoE is a chronic disease that will require long-term follow-up and treatment.

3. Inclusion of the term immune/antigen driven. An increasing body of clinical, translational, and basic evidence supports a role of an aberrant immune response (potentially reversible with treatment) as an underlying pathogenetic feature of EoE.

4. Continued use of the word clinicopathologic. No biomarker or pathognomonic element has been identified that would eliminate the need for both symptoms and an abnormal histology to make the diagnosis.

5. No change in threshold number of 15 eosinophils/hpf. Since the $2007 \mathrm{CR}$, no studies have identified a clear "lower limit of esophageal eosinophilia" or threshold number that would define EoE or have identified other histologic features or pattern of disease distribution that are pathognomonic of EoE.

6. No change in the use of hpf as the unit of measurement for eosinophilia. No studies have yet determined a standardized size of an hpf, and this might be practically unachievable. This issue is problematic because the size of an hpf can alter the reported number of eosinophils per hpf.

7. Inclusion of topical steroids/diet exclusions as a treatment. Current clinical evidence exists to include this paradigm to differentiate EoE from other diseases. Other potential therapies might exist but have not yet been supported in the literature.

8. Exclusion of GERD reference. A number of other causes of esophageal eosinophilia have been identified, and a broader statement has been included that allows for clinical discretion to be used.

9. Inclusion of patients with less than 15 eosinophils/hpf. A small number of patients with EoE (and who are treated with a PPI) might have less than the threshold number of eosinophils on their mucosal biopsy specimens associated with other features of eosinophilic inflammation, including microabscess formation, superficial layering, or extracellular eosinophil granules. Potential reasons for this finding include but are not limited to inadequate biopsy specimens, sampling error, chronic disease, or partial treatment response.

10. Inclusion of the term PPI-responsive esophageal eosinophilia. Therapeutic/basic studies and clinical experience have identified a potential antiinflammatory or barrier-healing role for proton pump inhibition in patients with esophageal eosinophilia.

For optimal pathologic evaluation, multiple biopsy specimens from the proximal and distal esophagus should be obtained and evaluated for a variety of pathologic features. Pathologists should report all abnormalities associated with EoE, such as the peak eosinophil value (obtained from the area with the highest density of eosinophils), eosinophilic microabscesses, surface layering of eosinophils, extracellular eosinophil granules, basal cell hyperplasia, dilated intercellular spaces, and lamina propria fibrosis. In a few circumstances patients might have strong clinical evidence for EoE and have less than 15 eosinophils/hpf, with other histologic features indicative of eosinophilic inflammation.

An emerging body of literature and clinical experience describes a subset of patients whose symptoms and histopathologic findings are responsive to PPI treatment and who might or might not have well-documented GERD. Until more is known regarding this subgroup of patients, these patients should be given diagnoses of PPI-responsive esophageal eosinophilia. Future studies should be performed to determine whether PPIs help to diminish an immune/antigen-driven response, as is known to occur in patients with EoE.

\section{SUMMARY OF LITERATURE SINCE THE 2007 CR History and physical examination \\ Update of $\mathbf{2 0 0 7}$ recommendations. Several studies have} confirmed previously described clinical features of EoE, but no pathognomonic features have been identified. Clinical manifestations of EoE in children are nonspecific and vary by age such that diagnosis based on symptoms alone is not feasible. Infants and toddlers often present with feeding difficulties, whereas school-aged children are more likely to present with vomiting or pain. ${ }^{46,47}$ Dysphagia is a predominant symptom in adolescents. EoE in children is most often present in association with other manifestations of atopic diathesis (food allergy, asthma, eczema, chronic rhinitis, and environmental allergies) and is responsive to elimination of specific dietary antigens in that population.

The typical patient with EoE is an atopic male (male/female ratio, 3:1) who presents in childhood or during the third or fourth decades of life; however, EoE can occur at any age. ${ }^{48,49}$ EoE occurs in most racial and ethnic groups, although many studies have reported predominance in non-Hispanic whites; the reason for this requires further investigation. ${ }^{50-54}$ Physical examinations are useful in children to identify normal growth patterns and in both children and adults to identify comorbid allergic diseases; however, no features on physical examination are specific in making the diagnosis of EoE. In addition, no oral or pharyngeal manifestations of EoE have been identified, although some children who have EoE might present with laryngeal symptoms. ${ }^{55}$

Symptoms in adult patients with EoE are somewhat stereotypical and include dysphagia, chest pain, food impaction, and upper abdominal pain. Solid-food dysphagia continues to be the most common presenting symptom. ${ }^{48,49,56,57}$ When examining all patients presenting with dysphagia in endoscopy units, EoE has a prevalence of up to $15 \%{ }^{56,57}$ In some series chest pain is the second leading symptom in adults with EoE. ${ }^{6,58}$ Whether chest pain from EoE can be differentiated from GERD or is due to esophageal hypersensitivity to acid remains to be determined. ${ }^{6,58,59,60}$ Food impaction necessitating endoscopic bolus removal occurs in $33 \%$ to $54 \%$ of adults with EoE. ${ }^{61}$ Upper abdominal pain, symptoms of GERD, and nonspecific throat symptoms, including globus, have also been reported in some adults with EoE. Recent clinical observations suggest that chest discomfort associated with EoE might have different features than those reported in patients with GERD.

A subgroup of patients has been increasingly recognized who have (1) a typical EoE symptom presentation, (2) have had GERD diagnostically excluded, and (3) demonstrated a clinicopathologic response to PPIs. ${ }^{6,58,59,62,63}$ Terms used to describe these patients include PPI-responsive esophageal eosinophilia and PPI-responsive $E o E$. The latest term is controversial because limited evidence to support the effect of PPIs in an "immune/antigen-driven" inflammatory response exists. Potential explanations include healing of a disrupted epithelial barrier to prevent further immune activation, decreased eosinophil longevity, inherent anti-inflammatory properties of PPIs, or unreliable diagnostic testing. ${ }^{64-67}$

A validated symptom-assessment tool is not available, such that recent studies attempting to correlate symptoms with histology 
have too little objective basis and have yielded conflicting results. Some studies found such a correlation, ${ }^{40,49,62,68,69}$ and others did not. ${ }^{57,70-72}$ The correlation of symptom severity with the density of esophageal eosinophilia is therefore still controversial and is currently insufficient to permit either diagnosis at presentation or a critical assessment of the efficacy of therapy. The absence of symptoms in the face of active inflammation is particularly problematic because it is uncertain whether persistent inflammation will result in complications such as stricture formation.

Committee clinical recommendations. Any patient with symptoms suggestive of EoE should undergo a careful history, with a particular focus on eating and swallowing habits. Both children and adults with EoE often rapidly adapt eating habits to manage their impaired esophageal function; a number of these compensatory behaviors will escape detection unless the clinician maintains a high index of suspicion (see Table E1 in this article's Online Repository at www.jacionline.org).

In children physical examination is essential to assess parameters of growth and nutrition that might be affected by the effect of the disease itself (eg, feeding difficulties that limit intake) or by attempts at therapy that involve severe dietary restrictions. Appropriate evaluations should be undertaken when signs indicative of other conditions that might involve the esophagus (eg, Crohn disease and eosinophilic gastroenteritis) or that might mimic the condition (eg, GERD and achalasia) are present.

Because an emerging group of patients with PPI-responsive esophageal eosinophilia has been identified, clinical judgment, as well as information derived from therapeutic response to PPI, $\mathrm{pH}$ monitoring, or both, should be taken into careful consideration to distinguish esophagitis related to GERD from that caused by EoE. PPI responsiveness or diagnostic testing ( $\mathrm{pH}$ monitoring) might not adequately distinguish GERD and EoE.

Committee future recommendations. Validated symptom-assessment tools that can be used to discriminate EoE from other causes of esophageal eosinophilia and to monitor the effect of treatments in therapeutic trials are urgently needed. Studies to identify a reliable biomarker of inflammation will be required to limit the number of endoscopies needed to confirm control over the inflammatory process. Additional mechanistic studies clarifying PPI-responsive esophageal eosinophilia will aid in our understanding of the pathogenesis of EoE. In the future these studies could also use translational methods (eg DNA microarrays or specific gene and protein levels through immunochemistry, ELISA, or both) to incorporate biologic measures to further refine the clinical definition of EoE.

\section{Endoscopic and radiologic features}

Update of $\mathbf{2 0 0 7}$ recommendations. A number of studies have confirmed the presence of esophageal abnormalities identifiable by means of endoscopy in patients with EoE, including fixed esophageal rings (sometimes called corrugated rings or trachealization), transient esophageal rings (sometimes called feline folds or felinization), whitish exudates, longitudinal furrows, edema, diffuse esophageal narrowing, narrow-caliber esophagus, and esophageal lacerations induced by passage of the endoscope (a manifestation of mucosal fragility that, when severe, gives the esophagus the appearance of crepe paper). However, because all of these endoscopic features have been described in other esophageal disorders, none can be considered pathognomonic for EoE.
Two studies have provided information on the diagnostic utility of these endoscopic findings. In one study of 222 patients with dysphagia who had endoscopy with esophageal biopsy, 33 (15\%) had histologic evidence of EoE. ${ }^{57}$ Among 21 patients who had endoscopic features suggestive of EoE, the diagnosis was confirmed by means of biopsy in only 8 (38\%). Ten (9.8\%) of 102 patients with a normal endoscopic examination had histologic evidence of EoE. Esophageal eosinophilia was frequently found in patients who had other causes of dysphagia (eg, reflux esophagitis and peptic stricture). Another study described similar findings. ${ }^{56}$ Among 261 patients with dysphagia who had endoscopy with esophageal biopsy, 31 (12\%) had histologic evidence of EoE. However, only 12 (34\%) of 35 patients with esophageal rings seen on endoscopy were confirmed to have esophageal eosinophils on biopsy. The optimal number of mucosal biopsy specimens that should be obtained to maximize the diagnostic yield of EoE has begun to be addressed. ${ }^{73,74}$ By using 15 eosinophils/ hpf as a threshold for diagnosis, one study identified a diagnostic sensitivity of $84 \%, 97 \%$, and $100 \%$ for obtaining 2, 3, and 6 biopsy specimens, respectively. ${ }^{73}$

Barium contrast radiography can identify a number of the anatomic and mucosal abnormalities of EoE, but the sensitivity of radiography as a diagnostic test for this condition appears to be low. One study found that barium swallow results were normal in 12 of 17 children with EoE, including 4 who had endoscopy for food impaction. ${ }^{75}$

Committee clinical recommendations. Endoscopy with esophageal biopsy remains the only reliable diagnostic test for EoE. However, the finding of isolated esophageal eosinophilia without determining corroborating symptoms and ruling out other causes of esophageal eosinophilia is inadequate to make the diagnosis of EoE. In the appropriate clinical setting the finding of any of the endoscopic features described above supports but does not establish the diagnosis of EoE (see Table E2 and Fig E1 in this article's Online Repository at www.jacionline.org). Esophageal biopsy specimens should be taken to seek histologic evidence of EoE in patients with unexplained dysphagia, even if results of endoscopy appear normal or identify a potential cause of dysphagia other than EoE.

Two to 4 mucosal biopsy specimens of the proximal and distal esophagus should be obtained. In children and, when indicated, in adults biopsy specimens of the gastric antrum and duodenum should be obtained once to exclude other potential causes of esophageal eosinophilia. There are limited data to support routine gastric or duodenal biopsies in adults in the absence of symptoms or endoscopic abnormalities suggesting other gastrointestinal disorders, although it is reasonable for these biopsies to be performed.

Radiography is not a recommended routine diagnostic test for EoE but can be helpful in selected cases not only to characterize anatomic abnormalities that can be difficult to define endoscopically but also to provide information on the length and diameter of complicated esophageal strictures. Findings of a narrowcaliber esophagus (see definition in the "Disease complications" section) or proximal cervical esophageal stricture might be overlooked. Communication with the radiologist regarding indications for the esophagram is important so that the entire esophagus, including the caliber and distensibility of the esophageal lumen, will be fully assessed.

Committee future recommendations. Further studies are needed to determine agreement among endoscopists in 
identifying the endoscopic features of EoE and to define the diagnostic utility of the individual endoscopic features of EoE. ${ }^{73,74}$

\section{Histologic findings}

Update of 2007 recommendations. Eosinophils and extracellular eosinophil granules. No prospective studies have determined a threshold number of esophageal eosinophils that can establish a diagnosis of EoE with high specificity and sensitivity and consistently allow differentiation of EoE from other causes of esophageal eosinophilia. One study that related peak eosinophil counts in esophageal biopsy specimens from patients with EoE to symptom frequency or severity reported a lack of correlation between eosinophil density and symptoms in untreated patients with new diagnoses. ${ }^{70}$ However, another study that correlated a composite score found some correlation between symptom subcomponents (dysphagia and anorexia/early satiety) and inflammation. ${ }^{46}$ Pediatric patients who had esophageal biopsy specimens obtained between 1982 and 1999 with 15 or more eosinophils/hpf and as few as 5 or more eosinophils/hpf were significantly more likely to have increased eosinophil numbers in subsequent esophageal biopsy specimens. Surface layering and microabscesses were found only in biopsy specimens that had 15 or more eosinophils/hpf. ${ }^{76}$ These data are supported by a case-control study that found that the odds ratios for the findings of basal zone hyperplasia and extracellular eosinophil granules were 44 and greater than 100 for patients with EoE (defined as $>20$ eosinophils/hpf) versus those without EoE, respectively. In that study epithelial desquamation and microabscesses were present only in patients with greater than 20 eosinophils/hpf. ${ }^{77}$

Some studies have shown that significant eosinophilic inflammation occurs in the proximal esophagi of adults with EoE but not GERD $^{78}$; others have not confirmed this finding. ${ }^{6}$ Previous studies reported patients with EoE with increased eosinophil numbers in the distal esophagus. ${ }^{79}$ Some have found that a significant proportion of adult patients with greater than 15 eosinophils/hpf had GERD/PPI-responsive esophageal eosinophilia. ${ }^{6}$ Currently, neither histopathology nor distribution of inflammatory changes in esophageal biopsy specimens predicts response to PPI therapy. However, eosinophilic microabscesses and surface layering of eosinophils are more typical of findings associated with EoE than GERD. In a limited number of patients, the presence of extracellular eosinophil granules (depicted by extracellular deposition of granule proteins, including eosinophil peroxidase, major basic protein, and eosinophil-derived neurotoxin) was found to be a useful feature for histologic distinction of EoE from GERD. ${ }^{80-82}$ One pediatric study showed that basal cell hyperplasia and extracellular eosinophil granules correlated with symptoms. ${ }^{77}$

From a technical standpoint, one study identified a benefit of evaluating the peak number of eosinophils per hpf, as opposed to the average number, by using the number of eosinophils, extracellular eosinophil granules, epithelial changes, and eosinophils per hpf in patients with EoE. ${ }^{51}$ Unfortunately, the actual size of the hpf described in many studies is quite variable and frequently not reported. These limitations continue to create significant problems in comparing data across institutions and between different studies. ${ }^{83}$

Associated histologic features and other cell types observed in patients with EoE. Lamina propria fibrosis is found in most biopsy specimens from children and adults with EoE and has been shown to be less prevalent in biopsy specimens from patients with GERD and healthy subjects. ${ }^{78,84,85}$ In some studies subepithelial fibrosis was one of the histologic features that improved after treatment with topical steroids or anti-IL-5 (mepolizumab). ${ }^{40,69}$ Other histologic findings, such as basal zone hyperplasia, elongation of rete pegs, and dilated intercellular spaces, are also consistently associated with EoE, but their diagnostic specificity is less certain. ${ }^{86,87}$ Some studies have also identified that mast cells are increased in biopsy specimens from patients with EoE compared with those from patients with GERD. ${ }^{24,41,81,88}$ IgE-bearing cells are more common in biopsy specimens from patients with EoE compared with those from patients with GERD and are also not detected in control specimens. ${ }^{24,41}$ The number of intraepithelial regulatory $\mathrm{T}$ cells are increased in esophageal biopsy specimens from patients with EoE and those with GERD compared with normal mucosa but are not significantly different when comparing EoE with GERD. ${ }^{29}$ B-cell numbers are increased in biopsy specimens from patients with EoE compared with those seen in control subjects as well. $^{41}$

In both murine and translational studies, the cytokine IL-5 remains a focal point. IL-5 has been identified in human biopsy specimens and has been shown to drive eosinophil-mediated esophageal remodeling in murine models. ${ }^{11,26,89}$ Periostin, an extracellular matrix protein associated with heart and lung repair and remodeling, has been shown to be increased in the esophagi of patients with EoE. The presence of periostin correlates with increased eosinophil levels in patients with EoE but not in patients whose eosinophil levels are less than the threshold criteria that were used to define EoE. ${ }^{90}$ Confirming and expanding prior genetic studies, expression of eotaxin-1/CCL11 and eotaxin-3/ CCL26 genes have been reported to be increased in biopsy specimens from patients with EoE compared with those seen in control specimens. ${ }^{91,92}$ Fibroblast growth factor 9, IL-13, IL-15, and TGF- $\beta 1$ levels are also increased in biopsy specimens from patients with EoE and patients with GERD compared with those seen in normal biopsy specimens. ${ }^{93}$

Committee clinical recommendations. Histopathologic features of esophageal mucosal biopsy specimens must be interpreted in conjunction with the patient's clinical information (see Table E3 in this article's Online Repository at www. jacionline.org and Fig 1) Until more specific studies are performed, it is important that all histologic features, including peak eosinophil counts obtained from the most densely populated hpf, eosinophil microabscess formation, superficial layering of eosinophils, extracellular eosinophil granules, basal cell hyperplasia, dilated intercellular spaces, rete peg elongation, subepithelial lamina propria fibrosis, and increases in numbers of other cell types, such as lymphocytes, be evaluated and noted in pathology reports. Inflammatory changes in patients with EoE might be focal and might not be present in all biopsy specimens from a single patient. Because of the nonspecific nature of symptoms in children, assessment of gastric and duodenal mucosa is recommended.

Committee future recommendations. Wide variations in practice patterns and clinical experience have created controversy and differences of opinion regarding the most optimal method of defining eosinophil-predominant inflammation. Although measurement of the absolute number of eosinophils per hpf has allowed identification of patients with EoE, the method remains problematic. Limitations of this method include lack of standardization of the size of an hpf, variability in the definition of an intraepithelial eosinophil in hematoxylin-stained tissue sections, and lack of information regarding the absolute threshold number of eosinophils that distinguishes EoE from other causes 


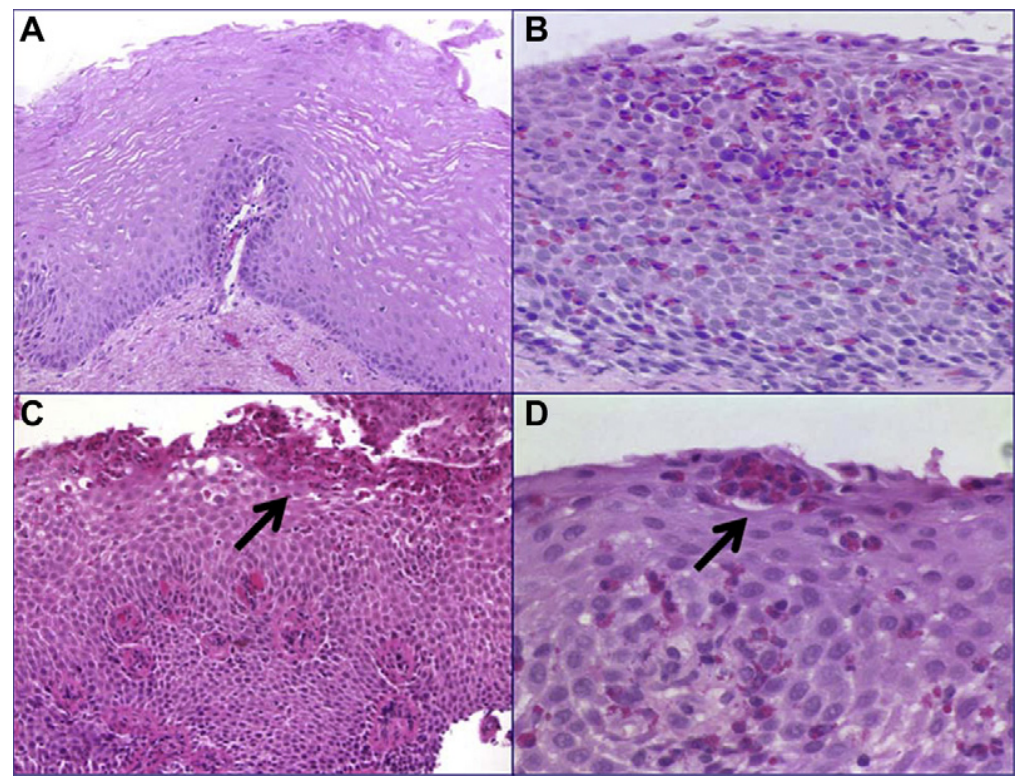

FIG 1. Histology of the esophagus (mucosal biopsy specimens). A, Normal esophagus. B, EoE. C, EoE, superficial layering of surface eosinophils (arrow). D, EoE, microabscess (arrow).

of esophageal eosinophilia. The diagnostic significance and specificity of other features of eosinophil-predominant inflammation, such as eosinophilic microabscess formation, superficial layering of eosinophils, and the presence of extracellular eosinophil granules, are also still unknown.

Prospective studies are needed to help identify histologic features that can differentiate EoE from other causes of esophageal eosinophilia, in particular GERD. Standardization of the unit for eosinophil enumeration (hpf vs square millimeters) might facilitate comparison of patients between different studies. Studies that validate associated features of inflammation (see Table E3) might allow discrimination between EoE and GERD and might also potentially allow differentiation of EoE phenotypes. Studies should address practical issues, such as the optimal number of tissue samples to survey, the anatomic location with the highest yield of diagnostic mucosal biopsy specimens (proximal/middle/distal), and the best method of quantitating eosinophils. ${ }^{7,94,95}$ Transcriptome analysis of mucosal samples might potentially determine novel pathogenetic mechanisms and allow for molecular diagnostics. Expression of eotaxin-3, periostin, COX-2, IL-5, IgE, and a large panel of EoE-specific transcripts (eg, EoE transcriptome) should be investigated in larger studies to determine whether they are helpful in distinguishing EoE from GERD.

\section{Other diagnostic modalities}

Update of 2007 recommendations. Studies before 2007 showed that in patients with reflux esophagitis, standard transnasal and wireless capsule pH-recording systems demonstrate variability in acid $\mathrm{pH}$ monitoring. ${ }^{66,67}$ One recent study detected significantly greater symptom association with the addition of impedance to $\mathrm{pH}$ testing compared with $\mathrm{pH}$ testing alone; however, the clinical implication of this association has not been determined. ${ }^{96}$ The performance characteristics of transnasal and wireless $\mathrm{pH}$ and combination $\mathrm{pH}$ impedance testing in patients with EoE are uncertain.

In a cohort study adults with esophageal eosinophilia in their mid and proximal esophagi without endoscopic evidence of erosive reflux disease underwent $\mathrm{pH}$ monitoring while off PPI therapy. ${ }^{6}$ At baseline, $\mathrm{pH}$ testing revealed that 15 (71\%) of 21 patients demonstrated pathologic acid reflux disease, whereas 6 did not. Both groups were then treated with twice-daily PPI therapy for 2 months and underwent follow-up endoscopy. Among subjects with pathologic acid reflux, $12(80 \%)$ had resolution of esophageal eosinophilia, suggesting the eosinophils might have been present in response to acid reflux. Three subjects had persistent eosinophilia despite PPI therapy because they might have had 2 diseases (GERD and EoE) or because they were nonadherent in taking their PPIs. Among the 6 subjects with baseline esophageal eosinophilia with normal $\mathrm{pH}$ test results, 2 (33\%) demonstrated resolution of their eosinophilia with PPI therapy, despite the lack of objective evidence for acid reflux disease, suggesting either a lack of diagnostic accuracy of the $\mathrm{pH}$-monitoring study to identify pathologic acid reflux at baseline or that PPIs have an independent mechanism for improvement of esophageal eosinophilia. Four $(66 \%)$ subjects demonstrated persistent esophageal eosinophilia, reflecting either classic EoE or lack of subject adherence to PPI therapy.

When studied systematically in pediatric patients, neither acid nor nonacid reflux occurs in patients with EoE in a manner that differs from that seen in age-matched control subjects. ${ }^{97,98}$ Other tests have assisted in understanding more about the pathophysiology of EoE but have not added effect in making the diagnosis of EoE. One study demonstrated that patients with EoE sensed $0.1 \mathrm{~N}$ hydrochloric acid earlier than comparison control groups. ${ }^{59}$ The association of motility disturbances with EoE remain controversial, with some studies demonstrating abnormalities, such as high amplitude contractions, increased esophageal pressurization, and disordered wave patterns, whereas others reveal normal motility. ${ }^{48,97,99-101}$ Prolonged esophageal manometry and $\mathrm{pH}$ testing in children with EoE found that ineffective peristalsis correlated with dysphagia in children with EoE compared with control subjects. ${ }^{97,100}$

Endoscopic ultrasonography has been shown to detect a greater mucosal and muscular thickness in patients with EoE compared with that seen in control subjects. ${ }^{97,99}$ Impedance planimetry (EndoFLIP; Crospon, Inc, Carlsbad, Calif), a technology that uses a 
bag filled with a conductive solution and multiple impedance electrodes to simultaneously measure pressure and volume, detected significant pathologic changes in esophageal wall compliance and distensibility, which could be an important measure of esophageal dysfunction in patients with EoE. ${ }^{102}$ Highresolution esophageal manometry with pressure topography demonstrated abnormal esophageal pressurization patterns in adults with EoE compared with that seen in patients with GERD or healthy control subjects and might reflect reduced esophageal compliance. ${ }^{101}$ Endoscopic confocal laser microscopy might detect structural changes not apparent on visible light (routine) endoscopy specific to EoE. ${ }^{94}$

Committee clinical recommendations. Esophageal $\mathrm{pH}$ monitoring (and $\mathrm{pH}$ impedance, where available) is a useful diagnostic test to evaluate for GERD in patients with esophageal eosinophilia. Other testing modalities do not yet offer clear clinical benefit in diagnostic testing.

Committee future recommendations. Well-designed studies to investigate the role of $\mathrm{pH}$ and $\mathrm{pH}$ impedance monitoring in patients with GERD and EoE are needed, particularly in adults with EoE, in whom differentiation between EoE and GERD appears to be more problematic than in children and adolescents. Analysis of esophageal dysfunction might provide vital information for monitoring disease progression and therapeutic response. Prolonged ambulatory motility monitoring, as opposed to stationary monitoring, can provide optimal insights because abnormalities might only be intermittently present in patients with EoE. Other testing modalities require further investigation.

\section{GENOTYPIC FEATURES OF ESOPHAGEAL EOSINOPHILIA}

A growing body of literature supports the immunologic basis and genotypic features of EoE. During the past 4 years, a number of studies have helped shape the new conceptual definition of EoE as an immune/antigen-mediated disease.

\section{Update of 2007 recommendations}

In the 2007 CR the basic genetic features of EoE were limited to one study identifying the esophageal transcriptome of patients with EoE and its distinction from the transcriptome of healthy patients, as well patients with nonspecific chronic esophagitis (likely reflux associated with esophageal peak eosinophils counts $\leq 6$ eosinophils/hpf). ${ }^{103}$ Studies have validated the expression of a unique EoE transcriptome and validated that it differentiates EoE from GERD, with eotaxin-3 being abundantly overexpressed in patients with EoE. ${ }^{91}$ IL-13 has been found to be specifically upregulated in the esophagi of patients with EoE and might function as a master regulator of the EoE transcriptome. ${ }^{22}$ By using prior results that focused on the correlation of the EoE transcriptome with eosinophil levels, recent studies identified specific genome-wide transcripts that correlate with IL-13 and mast cells. ${ }^{104,105}$ These transcripts do not fully overlap with the originally described eosinophil-associated transcriptome, suggesting the existence of unique mechanisms involved in esophageal inflammation. Notably, abnormal gene expression is primarily reversible with disease remission, although a set of epithelial differentiation genes has been shown to remain abnormal and might be important in predisposing to disease relapse. ${ }^{26,106}$

Genetic susceptibility loci discussed in the 2007 CR were limited to genetic variants identified in the eotaxin- 3 gene based on a candidate gene approach. Now, a genome-wide analysis, probing 550,000 common genetic variants in both a discovery and replication cohort from multiple institutions, has identified the first genome-wide EoE susceptibility locus at $5 \mathrm{q} 22 .{ }^{38}$ Two genes located in the susceptibility haploblock include thymic stromal lymphopoietin (TSLP), a cytokine involved in $\mathrm{T}_{\mathrm{H}} 2$ cell determination. In a broad analysis of genetic variants within 53 candidate genes involved in allergic responses, epithelial responses, or both, the TSLP gene was also identified as a strong susceptibility locus for EoE, particularly when atopy was controlled, providing strong collective evidence for the role of this pathway in EoE pathogenesis. ${ }^{39} \mathrm{~A}$ genetic variant in the TSLP receptor gene, located on a pseudoautosomal region of the X-chromosome, was also linked with EoE susceptibility in male patients, providing early insight into a potential mechanistic contribution for this pathway into disease pathogenesis and the known clustering of EoE in male patients. ${ }^{39}$ Additionally, a common deletion variant in the filaggrin gene (2282del4), originally identified as a major contributing gene to atopic dermatitis, was identified to be markedly overrepresented in patients with EoE compared with control subjects without EoE. ${ }^{32}$ Interestingly, the filaggrin association appeared to be independent of the presence of atopic dermatitis in patients with EoE. Finally, a pilot study suggested that particular genetic variants in the $T G F B$ gene might correlate with the presence of esophageal TGF- $\beta$ levels and response to therapy. ${ }^{69}$

Committee clinical recommendations. The clinical use of specific genotypes to predict EoE diagnosis, prognosis, or both is not yet ready for clinical application. However, esophageal gene expression is likely to emerge as a key molecular analysis that helps differentiate EoE from other states, including GERD, to determine glucocorticoid-responding and nonresponding patients and to distinguish treated EoE (particularly useful when patients are medically treated with topical steroids before a PPI-confirmed diagnosis of EoE has been made). Clearly, genetic factors contribute to EoE susceptibility, and a combination of common variants likely play a major role in specifying the particular patient phenotype.

Committee future recommendations. The committee values the need for larger and well-characterized cohorts for genome-wide and candidate gene analysis, particularly examining more rare genetics variants than included in traditional genome-wide association studies. Identifying specific genotypes of patients with esophageal eosinophilia who are resistant to PPI therapy (classic EoE) and those with PPI-responsive esophageal eosinophilia is warranted. Further analysis of the genetic variants that contribute to atopic features of EoE (including the apparent nonatopic EoE group) and determining the relationship of these variants to other atopy and GERD susceptibility loci are areas of research need. Multisite studies aimed at validating the value of the EoE transcriptome for molecular diagnosis are also needed. In addition, adequately powered studies using well-defined patient populations designed to distinguish EoE from other esophageal eosinophilic conditions are needed.

\section{GENERAL ALLERGIC EVALUATION Update of 2007 recommendations}

Since the last CR, a number of pediatric, adult, and experimental model EoE studies have extended the concept that EoE is an antigen-driven allergic condition, thus supporting the conceptual definition of EoE described above. EoE is often one of 
multiple concurrent allergic diatheses, with $28 \%$ to $86 \%$ of adults and $42 \%$ to $93 \%$ of pediatric patients having another allergic disease. ${ }^{53,107-112}$ Several studies have reported that $50 \%$ to $60 \%$ of patients with EoE have a prior history of atopy. ${ }^{53,107,113}$ Since 2007, the rates of allergic diatheses have been better described, especially among adults with EoE. The majority of patients with EoE have sensitization to food allergens, aeroallergens, or both based on positive skin prick test (SPT) responses or serum specific IgE test results. There is a subset of patients with EoE who are not sensitized to food allergens, aeroallergens, or both, as determined by using specific IgE testing. Current studies demonstrate local IgE production and increase Fc $\in$ RI-positive cell numbers in patients with EoE. ${ }^{41,42}$

IgE-mediated food allergy. The testing method and definitions of food allergy vary among studies, but estimates of IgEmediated immediate food hypersensitivity in patients with EoE range from $15 \%$ to $43 \%{ }^{53,107}$ Higher rates of food-induced anaphylaxis can occur in patients with EoE based on current data using established guidelines for the diagnosis of food-induced anaphylaxis. ${ }^{114}$ The presence of documented IgE-mediated food allergy can be a predictive factor for EoE in adult and pediatric patients. $^{3}$

Airway and cutaneous allergy: Allergic rhinitis, asthma, and eczema. Rates of allergic rhinitis, asthma, and eczema in children and adults with EoE range from $40 \%$ to $75 \%$, $14 \%$ to $70 \%$, and $4 \%$ to $60 \%$, respectively. ${ }^{32,77,107,109,111,115} \mathrm{Six}$ articles document seasonality associated with EoE diagnosis, suggesting a potential inciting role for aeroallergens in patients with EoE. ${ }^{3,53,108,110,116}$ In experimental EoE models perennial household allergens (dust mite and cockroach) and molds induce esophageal eosinophilia. ${ }^{117,118}$ Additional accumulating evidence supports EoE pathogenesis as a $\mathrm{T}_{\mathrm{H}} 2$-associated disease with increased levels of esophageal mast cells, IL-13, IL-5, TGF- $\beta 1$, IgE, and Fc $\in$ RI-positive cells. ${ }^{22,41,42,84,89,105}$ Esophageal remodeling appears to play a role in esophageal dysfunction in a process pathogenically similar to asthma. ${ }^{27,84,85}$

\section{Committee clinical recommendations}

A thorough evaluation by an allergist or immunologist is recommended because of the high rates of concurrent asthma, allergic rhinitis, eczema, and food allergy/anaphylaxis; the potential seasonality of EoE diagnoses; and the complex interplay among multiple allergic diatheses. Additional testing for asthma and allergies is recommended to improve the diagnosis and control of concurrent atopic diseases.

\section{Committee future recommendations}

Future publications should clearly document and use standard definitions of allergic rhinitis, asthma (including asthma severity and level of control), and food allergy (rather than sensitization) when assessing and documenting concurrent allergic diseases in patients with EoE. Studies that assess the clinical effect of a "nonallergic" EoE phenotype on disease progression, therapeutic response, or both would be of interest.

\section{LABORATORY EVALUATION \\ Peripheral eosinophil counts and eosinophil granule proteins}

Update of 2007 recommendations. Four studies have documented peripheral eosinophilia in adult and pediatric patients with EoE, with $40 \%$ to $50 \%$ having increased numbers of circulating eosinophils ( $>300-350$ per $\left.\mathrm{mm}^{3}\right)$. ${ }^{3,77,119}$ Peripheral eosinophilia decreases after successful esophageal topical corticosteroid therapy and can correlate with tissue eosinophil numbers $(r=0.68) .{ }^{120}$ One study suggests that esophageal eosinophils in patients with EoE express HLA-DR, invoking the capacity of eosinophils to act as antigen-presenting cells. ${ }^{121}$ Peripheral eosinophil cationic protein levels did not correlate with tissue eosinophil numbers, although there were statistically nonsignificant eosinophilic cationic protein decreases after therapy. ${ }^{120}$

\section{Cytokines and PBMCs}

Update of $\mathbf{2 0 0 7}$ recommendations. Several studies have sought to address potential peripheral EoE biomarkers and response to treatment. Multiplex plasma assays showed that patients with food allergy and EoE had increased levels and spontaneous dendritic cell release of IL-5 and IL-13. ${ }^{45}$ Plasma basic fibroblast growth factor and serum IL-15 levels have recently been reported to be increased in patients with EoE compared with those seen in control subjects, and IL-15 levels might decrease after medical treatment. ${ }^{104,122}$ Adults with EoE had significantly decreased levels of the serum chemokine thymus and activation-regulated chemokine after treatment with oral budesonide, but thymus and activation-regulated chemokine levels did not correlate with tissue eosinophil numbers. An intriguing study in adults with allergic eosinophilic gastroenteritis noted a phenotypic distinction between $T_{H} 2$ cells, with increased numbers of food allergen-specific IL- $5^{+} \mathrm{T}_{\mathrm{H}} 2$ cells in eosinophilic gastroenteritis but IL- $5^{-} \mathrm{T}_{\mathrm{H}} 2$ cells in IgE-mediated peanut allergy; this interesting observation warrants evaluation in patients with EoE. ${ }^{123}$

Emerging studies have identified candidate surrogate disease markers in patients with EoE. Areas of uncertainty include the degree of correlation with EoE disease activity and the ability of these markers to distinguish atopic persons with or without EoE.

Committee clinical recommendations. There is currently insufficient information to support the clinical utility of any single peripheral marker to function as a surrogate disease indicator of histologic inflammation in patients with EoE. Although peripheral eosinophil counts can correlate with tissue eosinophilia in some patients with EoE, if obtained, changes in peripheral eosinophilia should be interpreted with consideration for the patient's age, adherence to aeroallergen avoidance, pollen season, and control of comorbid allergic disease.

\section{Total IgE}

Update of 2007 recommendations. One additional pediatric and 2 adult studies support previous findings suggesting that total IgE levels are increased (>114 kU/L) in 50\% to 60\% of patients with EoE. ${ }^{109,111}$ Higher total IgE levels are reported in allergen-sensitized versus nonsensitized patients with EoE. Total IgE levels were not predictive of the therapeutic response in one study (budesonide) and did not decrease by 15 days of treatment.

Committee clinical recommendations. There are currently inadequate data to support the utility of measuring the total IgE level as a surrogate disease indicator of histologic inflammation in patients with EoE.

Committee future recommendations. Future candidate surrogate disease marker studies in patients with EoE should include large, multicenter, longitudinal studies of adult and 
pediatric patients with EoE compared with healthy, GERD, and atopic control populations. Reasonable peripheral marker candidates include IL-5, IL-13, IL-15, eotaxin-3, basic fibroblast growth factor, eosinophils, and antigen-specific T-cell subsets.

\section{Aeroallergen-specific IgE}

Update of 2007 recommendations. The presence of allergic rhinitis, sensitization to aeroallergens, or both ranges from $24 \%$ to $78 \%$ in adult patients and $42 \%$ to $93 \%$ in children with EoE. ${ }^{53,77,107,108,110,111,114,118,124}$

Several studies ( 2 pediatric and 1 adult) clearly documented the presence of aeroallergen-specific serum $\operatorname{IgE}$ in patients with EoE. ${ }^{77,109,111}$ Overall, $44 \%$ to $86 \%$ of patients have serum IgE to outdoor, indoor, or both inhalant aeroallergens. Thirty-two percent of pediatric patients had serum IgE to a cluster of aeroallergens that included pollens and grains, soy, and nuts/peanuts; $86 \%$ of adults have polysensitization to aeroallergens; and 61\% (11/18) of patients had birch-associated oral allergy syndrome. ${ }^{109,111}$

Current studies document rates of $71 \%$ to $93 \%$ for SPT positivity to aeroallergens in pediatric and adult patients with EoE. $^{3,111,114,118,119,124,125}$ Publications since 2007 have documented sensitization rates through SPTs to outdoor aeroallergens, including grass, weeds, trees, and molds (64\% to $93 \%)$, and indoor aeroallergens, including dog, cat, cockroach, and dust mites $(16 \%$ to $69 \%){ }^{77,107,108,111,116,118}$ Even in the pediatric population, inhalant sensitization was as high as food sensitization, and it is common for adult and pediatric patients to have polysensitization to aeroallergens.

Retrospective analyses show decreased EoE diagnosis in the winter and increased diagnosis in the spring, summer, and fall in a total of 583 pediatric and adult patients with EoE. ${ }^{3,53,107,108,110,116}$ Tree and grass pollen levels can directly correlate with the numbers of patients given a diagnosis of EoE.

Sensitization to pollens that cross-react with plant-derived food allergens might provide a link between pollen sensitization and subsequent food ingestion in triggering EoE, although studies to address this possibility are currently lacking.

Committee clinical recommendations. Because numerous studies document aeroallergen sensitization and seasonal variability in patients with newly diagnosed EoE, a complete evaluation of patients with EoE for aeroallergen sensitization is frequently warranted in both adult and pediatric patients because this might alter clinical management.

Aeroallergens might have a complementary role in EoE pathogenesis, and appropriate avoidance measures should be recommended. Treating physicians might want to consider a patient's aeroallergen sensitization profile and seasonality when assessing esophageal biopsy results in patients with EoE.

Committee future recommendations. Seasonality, whether driven by aeroallergens or the consumption of seasonal foods, requires further investigation. Studies that document clear EoE instigation, propagation, and/or exacerbation by aeroallergens in human subjects are warranted but likely difficult to perform because of the need for biopsy evaluation. Surrogate markers for EoE might help in this regard. Studies that document the effects of aeroallergen-specific immunotherapy in patients with EoE would be of interest. Prospective studies documenting aeroallergen sensitization in larger populations of patients with EoE and examining the potential correlation between seasonal variability in symptoms and relevant pollen sensitization are needed.

\section{Food-specific IgE}

Update of 2007 recommendations. Four articles documented serum specific IgE in patients with EoE. ${ }^{77,109,111,126}$ None of these studies documented the clinical significance of serum IgE sensitization to EoE diagnosis or management. Sensitization to foods is common in children with EoE, and one study suggested that food-specific IgE testing might be more sensitive than SPTs, but the significance of these positive test results remain unclear.

Current studies of adults with EoE indicate a higher rate of positive test results to foods than was appreciated before the 2007 CR. Among adult patients, $50 \%$ had positive results to at least 1 food, the most common being peanut (38\%), egg (27\%), and soy (23\%). ${ }^{125,127}$ Additional publications concerning children continue to show higher rates of positive test results to foods than generally reported from the adult studies. ${ }^{25,110,111,124}$ Although studies support a high rate of sensitization to foods in patients with EoE and a subset of patients with EoE might have acute allergic reactions to foods, warranting evaluation for IgE-mediated food allergies, there are limited data addressing the diagnostic value of SPTs for identifying foods that might directly contribute to EoE. In one study more than 20 subjects were evaluated for the relationship of SPT results to milk, egg, soy, wheat, corn, and beef to outcomes of dietary elimination in patients with EoE. ${ }^{25}$ Positive predictive value ranged from $57 \%$ to $96 \%$, negative predictive value ranged from $58 \%$ to $75 \%$, specificity ranged from $14 \%$ to $65 \%$, and sensitivity ranged from $90 \%$ to $98 \%$. Skin tests were slightly more sensitive than patch tests and generally less specific. Only one study documented predictive values for SPTs, and no studies documented predictive values for serum IgE-based dietary elimination. ${ }^{25}$ Local production of IgE in patients with EoE might explain a potential disconnect between positive test results and actual EoE food triggers. ${ }^{41}$

Several additional studies with regard to food atopy patch tests (APTs) have been reported. ${ }^{16,25,110,111,114,126,127}$ Positive patch test rates range from $30 \%$ to $95 \%$ in children and adults with negative predictive values of greater than $90 \%$ (except milk, with a negative predictive value of 50\%) and variable positive predictive values in children. ${ }^{127}$ Using SPT- and APT-based elimination diets, milk and egg were the most common EoE triggers in children. Food patch testing remains to be standardized and validated in children and adults. Evidence that APTs induce a local immune response reflecting the immunopathology seen in patients with EoE also remains to be demonstrated.

Committee clinical recommendations. Because of the high rates of food allergies and anaphylaxis in patients with EoE, serum IgE and skin prick testing for immediate-type food allergy is warranted to identify comorbid food-induced allergic disease in patients with EoE.

The clinical utility of $\operatorname{IgE}$ testing for dietary intervention in patients with EoE remains largely unknown. Medically supervised food reintroduction might be necessary for patients with previous allergic reactions to a food or IgE-mediated sensitivity documented by SPT responses, serum food-specific IgE levels, or both because loss of tolerance during food avoidance might result in significant reactions on reintroduction of the food. ${ }^{128-130} \mathrm{~Pa}$ tients with EoE who are found to have positive skin test results to foods should be appropriately evaluated for immediate hypersensitivity reactions and prescribed epinephrine, if indicated. Food triggers in patients with EoE can currently only be identified by documenting disease remission after specific food antigen elimination followed by EoE recrudescence on specific food 
reintroduction. As such, although SPTs, serum IgE tests, and food patch tests can be used to help identify foods that are associated with EoE, these tests alone are not sufficient to make the diagnosis of food allergy-driven EoE. ${ }^{131}$

Committee future recommendations. The clinical utility of serum food-specific IgE levels and SPT responses for generating successful food antigen elimination diets in patients with EoE and the use of commercial food extracts versus fresh foods for SPTs and APTs in patients with EoE require further investigation. Multicenter studies that standardize and validate food APTs in patients with EoE are needed. Future studies should clearly document clinical and histologic benefit from food APTs, SPTs, and/or serum IgE-directed dietary interventions. Studies that evaluate food antigen-specific PBMCs as an in vitro diagnostic test for food allergy in patients with EoE would be of interest. Further studies that evaluate the potential increased efficiency of combined testing methods (serum and/or SPT and/or APT) in directing successful dietary elimination in patients with EoE are needed.

\section{MEDICAL AND DIETARY THERAPY PPI therapy}

Update of 2007 recommendations. As previously reported in the $2007 \mathrm{CR}$, acid suppression continues to be an effective tool in fulfilling the diagnostic guidelines for EoE. PPI therapy is useful in treating patients with esophageal eosinophilia secondary to GERD. ${ }^{6,132,133}$ Patients with isolated esophageal eosinophilia who are treated with PPIs and have a significant improvement of their symptoms and esophageal eosinophilia either have GERD or a yet undefined PPI-responsive esophageal eosinophilia ${ }^{3,134}$; the lack of a clinicopathologic response to PPI treatment in patients adherent to the treatment regimen with compatible symptoms of EoE and isolated esophageal eosinophilia is consistent with the diagnosis of EoE (see the "Diagnostic guidelines" section). ${ }^{110}$ However, apart from PPI-responsive esophageal eosinophilia, PPIs might be useful as a cotherapy in patients with diagnosed EoE because they might alleviate symptoms related to secondary GERD, which might be present with EoE. ${ }^{59}$ PPI therapy alone is not effective as a primary treatment for patients with EoE.

Committee clinical recommendations. In many patients PPIs are useful to help eliminate GERD as a cause of esophageal eosinophilia. The recommended PPI dose that should be used to eliminate PPI-responsive esophageal eosinophilia is $20-40 \mathrm{mg}$, once or twice daily for 8 to 12 weeks in adults (depends on patient and chosen PPI), and $1 \mathrm{mg} / \mathrm{kg}$ per dose, twice daily for 8 to 12 weeks in children (for maximal dosing use adult recommendations). PPIs are useful in treating patients with EoE in whom GERD is a comorbid disease. Finally, although the mechanism of PPIs is thought to primarily involve acid blockade, PPIs might also affect esophageal eosinophilia by means of other mechanisms and thus be helpful in a subset of patients described as having PPI-responsive esophageal eosinophilia.

Committee future recommendations. Patients with EoE might have an enhanced sensitivity to acid, even in the absence of pathologic reflux defined by conventional $\mathrm{pH}$ criteria. As a result, the presence of both GERD and EoE in a patient might not represent simple coexistence but instead a synergistic mechanism. Therefore the committee recommends additional studies clarifying the relationship among esophageal acid exposure and its capacity to increase eotaxin-3 production, esophageal eosinophilia, and clinical symptoms. In addition, future studies are needed not only to clarify PPI-responsive esophageal eosinophilia but also the endoscopic and histologic features that might distinguish GERD from EoE. Emerging data suggest a potential role for endoscopic ultrasound, deep tissue biopsies to examine for lamina propria fibrosis, identification of activated mast cells, and evaluation of the esophageal transcriptome.

\section{Dietary therapy}

Update of 2007 recommendations. Dietary therapy continues to be effective in children given a diagnosis of EoE. The literature continues to demonstrate that the use of dietary therapy leads to near-complete resolution of both clinical and histologic abnormalities. ${ }^{10,135}$ One study suggested that dietary restriction might reverse esophageal fibrosis. ${ }^{136}$ Three dietary regimens have been shown to be effective: (1) the strict use of an amino acid-based formula, (2) dietary restriction based on multimodality allergy testing, and (3) dietary restriction based on eliminating the most likely food antigens. Similar results (clinical and histologic response) have been documented when using either method of dietary restriction; however, when compared with the administration of a strict elemental formula in allergic patients, elemental formula continues to be the most effective dietary therapy. ${ }^{137}$ Available data suggest that tolerance to foods associated with EoE is unlikely to develop spontaneously, even after prolonged elimination. ${ }^{110}$ Furthermore, methods to induce tolerance in patients with EoE have not been evaluated.

Committee clinical recommendations. Dietary therapy should be considered in all children given a diagnosis of EoE. Preliminary observations suggest that dietary restriction should also be considered for motivated adult patients with EoE. When deciding on the use of a specific dietary therapy, the patient's lifestyle, adherence to therapy, and family resources need to be considered. Consultation with a registered dietitian is strongly encouraged to ensure that proper calories, vitamins, and micronutrients are maintained. The committee suggests that foods proved to cause EoE continue to be restricted from the diet, whereas those foods not definitively proved to be antigenic can be reintroduced systematically, with careful observation for recurrence of EoE. Restriction of foods proved to trigger EoE might need to be continued indefinitely.

Committee future recommendations. The use of dietary therapy in adults requires further study. In addition, further research needs to be performed with regard to the effect of dietary restriction on esophageal fibrosis, quality-of-life issues, adherence to therapy, development of food antigen tolerance, nutritional effects and possible consequences of prolonged dietary restriction, and best ways to identify foods (eg, skin prick, serum IgE, and patch testing) that cause EoE.

\section{Corticosteroid therapy}

Update of $\mathbf{2 0 0 7}$ recommendations. Corticosteroids continue to be an effective therapy in children and adults given diagnoses of EoE. ${ }^{138}$ Steroids improve the clinicopathologic features of EoE in most patients; however, when discontinued, the disease almost always recurs. ${ }^{139}$ Systemic corticosteroids can be used for emergency cases, such as severe dysphagia, hospitalization, and weight loss. ${ }^{140}$ Because of the potential for significant toxicity, the long-term use of systemic steroids is not recommended. Topical corticosteroids continue to be effective in inducing EoE remission, although steroid resistance (as demonstrated by the lack of histologic responsiveness and the failure to modify local esophageal gene expression) has been 
reported. ${ }^{33}$ Additional studies have documented their short-term safety, except for local fungal infections. Before 2007, fluticasone was primarily used. Since then, oral viscous budesonide has also been shown to be effective. ${ }^{12,120}$ Moreover, there is some evidence that budesonide can reverse esophageal fibrosis. ${ }^{69}$

Committee clinical recommendations. Topical corticosteroid therapy should be considered in all children and adults given a diagnosis of EoE for both initial and maintenance therapy (Table III). The type and duration of steroid therapy depends on the disease severity, the patient's lifestyle, the ability of the patient to continue the medication, and family resources. Doses of various steroid preparations are listed in Table III. Clinical experience and concern for ongoing symptoms, esophageal inflammation, and complications of untreated disease has led to the recommendation that after induction of clinicopathologic remission, topical corticosteroid therapy might need to be maintained; however, long-term therapy must be individualized for each patient. When topical steroids are used chronically, in addition to observing for side effects, growth should be carefully monitored in children.

Committee future recommendations. Further studies are needed to clarify the specifics of topical steroid therapy. Most importantly, investigation needs to be performed regarding the most effective topical steroid dose required for initial disease treatment and maintenance therapy for both children and adults. In addition, further research needs to be performed with regard to steroid resistance, the effect of corticosteroids on esophageal fibrosis, the need to treat to histologic normalcy, quality-of-life issues, growth, consequences of prolonged use (eg, adrenal suppression), and steroid effects on bone density.

\section{Cromolyn sodium, leukotriene receptor antagonists, biologics, and other therapies}

Update of 2007 recommendations. No additional information has been reported with regard to the use of cromolyn sodium or leukotriene receptor antagonists in patients with EoE. Cromolyn sodium has no apparent therapeutic benefit for patients with EoE. Leukotriene receptor antagonists might induce symptomatic relief when given at high dosages; its use has no demonstrable effect on esophageal eosinophilia. ${ }^{141}$ In a single study anti-TNF- $\alpha$ had no benefit in patients with EoE. ${ }^{142} \mathrm{~A}$ few studies in a small number of patients have been published using anti-IL-5. The studies demonstrated a significant decrease in esophageal eosinophil numbers and improvement in a few parameters of esophageal remodeling; however, the clinical response was variable. ${ }^{40,143}$

Committee clinical recommendations. Treatment of EoE with cromolyn sodium, leukotriene receptor antagonists, and immunosuppressive agents (azathioprine or 6-mercaptopurine) for the treatment of EoE is not recommended. The lack of combined clinical and histologic benefit and potential side effects currently outweigh any potential benefit. Biologic agents await further clinical studies and are not recommended for routine use at the present time. ${ }^{144}$ Several additional studies on anti-IL-5 therapy are pending.

Committee future recommendations. Other potential agents for the treatment of EoE should be investigated. Potential future treatments include immunosuppressive agents and the use of mAbs, such as anti-IL-5, anti-IL-13, and anti-eotaxin. In addition, the study of serum biochemical markers might aid in the development of potential future therapies.
TABLE III. Recommended doses of corticosteroids for EoE

Topical swallowed corticosteroids

Initial doses (see references for preparation and administration information)

Fluticasone (puffed and swallowed through a metered-dose inhaler) Adults: $440-880 \mu \mathrm{g}$ twice daily

Children: $88-440 \mu \mathrm{g}$ twice to 4 times daily (to a maximal adult dose)

Budesonide (as a viscous suspension)

Children $(<10$ y): $1 \mathrm{mg}$ daily

Older children and adults: $2 \mathrm{mg}$ daily

Systemic corticosteroids

For severe cases (eg, small-caliber esophagus, weight loss, and hospitalization)

Prednisone: $1-2 \mathrm{mg} / \mathrm{kg}$

\section{DISEASE COMPLICATIONS}

\section{Update of 2007 recommendations}

In the $2007 \mathrm{CR}$, little information was available regarding the definitions, prevalence, and management of EoE complications, including food impaction, esophageal stricture, narrow-caliber esophagus, and esophageal perforation. The understanding of EoE complications is hindered by the lack of uniform definitions for these well-recognized problems. The wide ranges of reported prevalence figures reflect not only variability of definitions of these complications but also differences in patient selection, period of follow-up, and treatment patterns.

Food impaction was defined as an event occurring after food ingestion, where food matter is retained in the esophagus, requiring either an emergency physician visit or endoscopic intervention. Self-limited food retention or transient dysphagia after eating not requiring intervention would not qualify as food impaction in this definition. Although such a definition overlooks clinically significant but self-resolving impaction, the committee considered it preferable to a definition that arbitrarily designates duration or severity of symptoms or other less quantifiable outcome. By using the definition of food retention requiring endoscopic extraction, the prevalence of food impaction among larger adult series of patients with EoE ( $>50$ subjects) ranged from $30 \%$ to $55 \% .^{3,53,145,146}$ In addition to these cohorts, investigators have assessed patients presenting with esophageal food impaction to define the proportion of impactions occurring secondary to EoE. Adult series have reported that $11 \%$ to $55 \%$ of food impactions demonstrated EoE. ${ }^{61,147,148}$

Stricture definition is problematic, given that esophageal rings are a common manifestation of the disease state in adults and because rings imply some degree of esophageal stricture. Similar to Schatzki rings, the rings in patients with EoE have an axial length of less than a few millimeters. Strictures might be arbitrarily differentiated by a length of greater than $1 \mathrm{~cm}$. The committee considered rings and strictures as distinct entities, as reported in the literature. With respect to narrow-caliber esophagus, this is differentiated from a stricture by the generalized involvement of the majority of the esophagus. Although a radiographic definition might be preferable to endoscopic assessment, most reports of this outcome used a subjective endoscopic impression to classify patients. Stricture prevalence in larger adult series ranged from $11 \%$ to $31 \% .^{3,53,71,145,149-151}$ Narrow-caliber esophagus has a reported prevalence of approximately $10 \%$ in larger series., ${ }^{3,115,145}$

The definition of esophageal injury patterns should be examined on the basis of the following suggested classification scheme. A full perforation or Boerhaave syndrome is characterized by a full-thickness tear with esophageal or gastric contents in the chest 
cavity that requires surgical treatment, usually with thoracotomy, drainage, repair, and possible resection. A partial rupture is defined by limited air or contrast extravasation into the mediastinum, often manageable by using a conservative approach. Esophageal intramural tears are identified endoscopically as deep lacerations extending into the esophageal submucosa or radiographically by contrast extending outside the esophageal lumen but contained within the esophageal wall. Circumferential intramural dissection is defined by circular detachment of the esophageal mucosa and not associated with leakage of esophageal contents into the mediastinum or thoracic cavities.

There have been 19 patients with EoE reported with spontaneous or non-dilation-related perforation, and of the 14 spontaneous perforations, there were 2 full perforations and 12 partial tears. ${ }^{146,152-159}$ Five postendoscopy perforations without preceding esophageal dilation were partial tears. ${ }^{160-162}$ Of the 19 perforations reported, 7 patients required surgical intervention (ie, 4 primary repairs and 3 esophageal resections). None of the reported perforations have been fatal. Three cases of circumferential intramural dissection and numerous cases of spontaneous and endoscopy-associated esophageal intramural tears have been reported. ${ }^{146,158,159}$

A number of medical and dietary approaches have been studied for EoE. Limited data are available on the effect of these therapies on complications of EoE. The majority of data exist regarding the effect of topical steroids on the incidence of food impaction in adults with EoE. In a retrospective study of 21 adults treated with fluticasone for 6 weeks, the prevalence of food impaction decreased from $71 \%$ to $0 \%{ }^{163}$ A prospective study reported food impaction in $83 \%$ before therapy and $0 \%$ after 12 weeks of fluticasone. ${ }^{151}$ The 15-day treatment period in a randomized controlled trial of budesonide allowed for detection of a significant improvement in dysphagia but was too short a treatment period to determine an effect on food impaction. ${ }^{133}$ A randomized controlled trial of fluticasone for 6 weeks reported food impaction in $81 \%$ of patients receiving placebo and $76 \%$ of those receiving fluticasone. After therapy for 6 weeks, no food impactions were observed in either group. A retrospective study of 32 adults with EoE who were contacted a mean of 3 years after therapy with 6 weeks of fluticasone observed recurrent dysphagia in $91 \%$ and food impaction in $28 \%{ }^{139}$ Available data on systemic steroids and elimination and elemental diets have been largely confined to pediatric studies in which the baseline prevalence of food impaction was either low $(<20 \%)$ or not reported.

Although concerns of additional long-term complications of esophageal cancer and progression of EoE to a generalized eosinophilic disorder exist, there has been no evidence of such complications to date. Six case reports have described patients with coexistent Barrett esophagus and possible EoE, one of whom had low-grade dysplasia. ${ }^{164-167}$ The finding of Barrett esophagus in patients with EoE does not imply causality given the high prevalence of GERD and Barrett esophagus in the general population.

\section{Committee clinical recommendations}

The diagnosis of EoE should be considered in patients presenting with food impaction, unexplained esophageal strictures, narrow-caliber esophagus, and spontaneous or endoscopic esophageal perforation. Clinicians should be aware of the risk of esophageal perforation in the setting of food impaction and with diagnostic endoscopy in patients with EoE.

\section{Committee future recommendations}

Standardized definitions for EoE complications of esophageal stricture, narrow-caliber esophagus, food impaction, and perforation are needed. Symptom assessment of self-limited food impaction is of clinical importance but difficult to define for research studies. Future studies on EoE should incorporate standardized definitions of complications of EoE to allow more accurate comparisons of outcomes across studies. Greater attention is needed to assess the effect of EoE and EoE therapy on patient-reported quality of life. Natural history studies are needed to define the long-term risks of EoE in terms of progression of disease and consequences of esophageal inflammation.

\section{ESOPHAGEAL DILATION Update of 2007 recommendations}

A number of reports have described the use of esophageal dilation to address stricture formation in patients with EoE. Initial reports of complications related to esophageal dilation in patients with EoE included not only chest pain but also perforation. Of the 84 adult patients reported before 2008 who underwent dilation, $5 \%$ experienced an esophageal perforation and $7 \%$ were hospitalized for chest pain, rates substantially higher than those quoted for esophageal dilation for other benign strictures. ${ }^{168}$ Such findings led to the 2007 recommendation that medical or dietary therapy for EoE be attempted before the performance of esophageal dilation. $^{1}$

Three recent retrospective studies from adult centers reported complication rates, secondary to perforation or resulting pain, requiring hospitalization rates that were considerably lower than those of initial reports. ${ }^{71,169,170}$ Only 3 perforations were reported among 404 patients undergoing 839 esophageal dilations. Incorporating this recent information for esophageal dilation of patients with EoE, the perforation rate is $0.8 \%$, and the chest pain rate is $5 \%$. Furthermore, perforations that did occur were partial ruptures and mainly determined by means of extravasation of air and not contrast or gastric contents. None of the reported perforations required surgical intervention. In the largest study postprocedural pain was reported in $5 \%$ on chart review but in $74 \%$ on a patient-reported questionnaire. Major bleeding defined by need for endoscopic hemostasis or blood product transfusion was reported in only 1 patient.

In spite of the greater safety margin reported in these recent studies of esophageal dilation, the optimal role of dilation as therapy of EoE is still controversial and should be individualized until more data are available. ${ }^{168}$ Dilation can provide immediate and long-lasting relief of dysphagia in patients with high-grade esophageal strictures. In adults EoE occurs primarily in otherwise healthy young to middle-aged patients, who, if given the option, might prefer periodic dilation to regular use of a medication or an elimination diet. A very high degree of patient acceptance for primary therapy with esophageal dilation was reported in a postdilation survey. ${ }^{71}$ Furthermore, although symptom response after medical and dietary therapy is high, the reversibility of esophageal strictures is poorly studied. On the other hand, the greater safety reported in the recent larger series might reflect the adoption of a more careful and conservative approach by experienced gastroenterologists aware of the potential hazards of dilation in patients with EoE. Finally, monotherapy with dilation does not address the underlying inflammatory process. ${ }^{71}$ 

1. Optimization of methodologies for histologic analysis of mucosal samples
A. Number of biopsy specimens
B. Proximal versus distal biopsy specimens
C. Number of hpfs that need to be examined
D. Effect of associated histologic features on diagnostic sensitivity
E. Mean versus peak number of eosinophils
F. Size of hpf used to quantitate eosinophils
G. Use of completely filled versus partially filled hpfs
H. Reporting eosinophil density as number per hpf versus number per unit area $\left(\mathrm{mm}^{2}\right)$
I. Eosinophil degranulation and optimal markers (MBP, EPO, and EDN)
2. Exclusion of esophageal acid/nonacid disease (PPI therapy and diagnostic testing)
3. Lack of consensus on criteria to diagnose eosinophilic disease in the remainder of the gastrointestinal tract
4. Allergy testing in adults and children in guiding dietary exclusions
5. Optimal end points of treatment (eg, symptom relief and histologic normalcy)
6. Frequency of endoscopy in follow-up (Is it needed in asymptomatic patients?)
7. Maintenance treatment (dose and duration)
8. Validated measurements of symptoms, endoscopic findings, histology, and quality of life

$E D N$, Eosinophil-derived neurotoxin; $E P O$, eosinophil peroxidase; $M B P$, major basic protein.

\section{Committee clinical recommendations}

Esophageal dilation with or without concomitant medical or dietary therapy can provide relief of dysphagia in selected patients with EoE. In the absence of high-grade esophageal stenosis, a trial of medical or dietary therapy before performance of esophageal dilation is reasonable. For high-grade strictures, dilation before initiation of medical therapy has been well tolerated and effective. The risk of chest pain after dilation is significant and should be discussed with patients. The use of esophageal dilation as primary therapy without concomitant medical or dietary therapy does not address the underlying inflammatory process and has been inadequately studied. On the other hand, the degree to which esophageal strictures will reverse with medical or dietary therapy alone is uncertain.

Although the risk of perforation is low, a more conservative and careful approach in the esophageal dilation technique is advised for patients with EoE compared with those with other benign entities, such as Schatzki ring or peptic stricture. Techniques described for esophageal dilation in patients with EoE include the use of both through-the-scope and bougie dilators. Bougies might be preferred because the esophageal lumen can be narrowed in multiple sites and sometimes diffusely. Advocates of through-thescope balloons point to 2 theoretical advantages: they apply exclusively radial force during dilation and afford the ability to immediately assess esophageal injury. The practice of gradual esophageal dilation with a target goal of 15 to $18 \mathrm{~mm}$ and limiting the progression of dilation diameter per session to $3 \mathrm{~mm}$ or less after resistance is encountered is reasonable but has not been specifically addressed in patients with EoE. Furthermore, this dilation approach has not been validated and applies to bougie and not through-the-scope balloon dilation. Multiple dilation sessions are often required for high-grade esophageal stenosis in patients with EoE. Monitoring progressive dilations during a single session with repeat endoscopy to examine for mucosal tears is controversial. This is more readily achieved with through-thescope balloons and more cumbersome with bougie dilation. Complications of dilation can be associated with younger age and more dilations, narrowing in the upper third of the esophagus, and inability to traverse the narrowing with the scope before dilation. ${ }^{170,171}$ These predictors of risk were largely based on inclusion of esophageal intramural tears as a complication.
Although such tears have been described in patients with EoE, there is no information that suggests that these tears represent anything more than a successful dilation.

\section{Committee future recommendations}

Prospective studies are needed to define the role of esophageal dilation in the management of EoE. Such studies will help define technical factors to optimize response and minimize risk of dilation. Studies are also needed to assess the degree of stricture response to medical and dietary therapy of EoE that would obviate the need for esophageal dilation.

\section{CONCLUSIONS AND FUTURE GOALS}

Since the initial set of recommendations and guidelines published in 2007, there has been a significant increase in clinical experience and the number of publications on the subject of EoE. However, despite the growing interest and ever-increasing body of literature, a great deal remains unknown (Table IV). Because of the confusion between esophageal eosinophilia and EoE, we provided both a conceptual definition of and diagnostic guidelines for EoE to assist clinicians in identifying the differences between histologic findings and the disease process. In addition, we anticipate that this definition and guideline will help to shape future research focusing on critical clinical and pathogenetic questions. As clinical experience broadens and research discovers more intriguing features of this disease, modifications of the presented definition and guideline are inevitable. Future challenges include developing appropriate translational studies that will allow definition of EoE phenotypic subsets. Of importance is the need to differentiate EoE from GERD, which has caused much controversy. Other important questions that mandate future research surround allergic testing, treatment approaches, the genetic basis of the disease, and diagnostic criteria, including molecular markers, the use of dilation, and the management of the complications of EoE.

The joint effort of pediatric and adult clinical and basic scientists in a variety of subspecialties has been paramount in the rapid understanding of this disease process. It is critical that leaders from all of the above specialties continue to work together and undertake studies on natural history, pathophysiology, biomarkers, diagnosis, and therapeutic approaches not only to 
increase the scientific and clinical knowledge of EoE but also to improve the lives of children and adults affected by the disease.

We thank Wendy Moore, MS, for her outstanding technical and administrative support and Mark Holbreich, MD, for his thoughtful and timely review of the manuscript. We also thank the following groups and persons for their ongoing dedication and support for the manuscript, patient advocacy, education, and/or research for eosinophilic esophagitis: the American Academy of Allergy, Asthma \& Immunology (www.aaaai.org); the American Gastroenterological Association (www.gastro.org); the American Partnership for Eosinophilic Disorders (www.apfed.org); the Bunning Family; the Children's Digestive Health and Nutrition Foundation (www.cdhnf.org); the Campaign for Urging Research for Eosinophilic Disease (www.curedfoundation.org); the Food Allergy Initiative; the North American Society of Pediatric Gastroenterology, Hepatology and Nutrition (www.naspghan.org); the National Institutes of Health (www. nih.gov); and the International Gastrointestinal Eosinophil Researchers (www. tiger-egid.cdhnf.org). Finally, we are extremely grateful to all of the patients and families for their participation and support of EoE research.

\section{What do we know?}

- EoE is a clinicopathologic disease isolated to the esophagus.

- EoE represents a chronic, immune/antigen-mediated, esophageal disease characterized clinically by symptoms related to esophageal dysfunction and histologically by eosinophil-predominant inflammation.

- With few exceptions, 15 eosinophils/hpf (peak value) is considered a minimum threshold for a diagnosis of EoE.

- Endoscopy with biopsy is currently the only reliable diagnostic test for EoE.

- An allergy evaluation is warranted in patients given a diagnosis of EoE.

- The disease should remit with treatments of dietary exclusion, topical corticosteroids, or both.

\section{What is still unknown?}

- Pathophysiology of PPI-responsive esophageal eosinophilia

- Pathognomonic features that define EoE

- Optimal histologic descriptive elements that characterize EoE

- Biomarkers and molecular signatures that aid in the diagnosis of EoE

- Therapeutic/predictive accuracy of skin prick and patch testing in patients with EoE

- Therapeutic value of dietary therapy in adults with EoE

- Natural history of EoE and rates and predictive indexes of complications (food impaction, esophageal stricture, and esophageal narrowing)

- Importance of treating asymptomatic patients with isolated esophageal eosinophilia

\section{REFERENCES}

1. Furuta GT, Liacouras CA, Collins MH, Gupta SK, Justinich C, Putnam PE, et al. Eosinophilic esophagitis in children and adults: a systematic review and consensus recommendations for diagnosis and treatment. Gastroenterology 2007;133: 1342-63.

2. Spergel JM, Book WM, Mays E, Song L, Shah SS, Talley NJ, et al. Variation in prevalence, diagnostic criteria, and initial management options for eosinophilic gastrointestinal diseases in the United States. J Pediatr Gastroenterol Nutr 2011;52:300-6.
3. Dellon ES, Gibbs WB, Fritchie KJ, Rubinas TC, Wilson LA, Woosley JT, et al. Clinical, endoscopic, and histologic findings distinguish eosinophilic esophagitis from gastroesophageal reflux disease. Clin Gastroenterol Hepatol 2009;7: 1305-13; quiz 1261.

4. Ngo P, Furuta GT, Antonioli DA, Fox VL. Eosinophils in the esophagus-peptic or allergic eosinophilic esophagitis? Case series of three patients with esophageal eosinophilia. Am J Gastroenterol 2006;101:1666-70.

5. Rodrigo S, Abboud G, Oh D, DeMeester SR, Hagen J, Lipham J, et al. High intraepithelial eosinophil counts in esophageal squamous epithelium are not specific for eosinophilic esophagitis in adults. Am J Gastroenterol 2008;103:435-42.

6. Molina-Infante J, Ferrando-Lamana L, Ripoll C, Hernandez-Alonso M, Mateos JM, Fernandez-Bermejo M, et al. Esophageal eosinophilic infiltration responds to proton pump inhibition in most adults. Clin Gastroenterol Hepatol 2011;9:110-7.

7. Dellon ES, Fritchie KJ, Rubinas TC, Woosley JT, Shaheen NJ. Inter- and intraobserver reliability and validation of a new method for determination of eosinophil counts in patients with esophageal eosinophilia. Dig Dis Sci 2010;55:1940-9.

8. Odze RD. Pathology of eosinophilic esophagitis: what the clinician needs to know. Am J Gastroenterol 2009;104:485-90.

9. Spechler SJ, Genta RM, Souza RF. Thoughts on the complex relationship between gastroesophageal reflux disease and eosinophilic esophagitis. Am J Gastroenterol 2007;102:1301-6.

10. Molina-Infante J, Ferrando-Lamana L, Mateos-Rodriguez JM, Perez-Gallardo B, Prieto-Bermejo AB. Overlap of reflux and eosinophilic esophagitis in two patients requiring different therapies: a review of the literature. World J Gastroenterol 2008; 14:1463-6.

11. Mishra A, Hogan SP, Brandt EB, Rothenberg ME. IL-5 promotes eosinophil trafficking to the esophagus. J Immunol 2002; 168:2464-9.

12. Mishra A, Rothenberg ME. Intratracheal IL-13 induces eosinophilic esophagitis by an IL-5, eotaxin-1, and STAT6-dependent mechanism. Gastroenterology 2003; 125:1419-27.

13. Akei HS, Mishra A, Blanchard C, Rothenberg ME. Epicutaneous antigen exposure primes for experimental eosinophilic esophagitis in mice. Gastroenterology 2005; 129:985-94

14. Blanchard C, Mishra A, Saito-Akei H, Monk P, Anderson I, Rothenberg ME. Inhibition of human interleukin-13-induced respiratory and oesophageal inflammation by anti-human-interleukin-13 antibody (CAT-354). Clin Exp Allergy 2005; 35:1096-103.

15. Spergel JM. Eosinophilic oesophagitis and pollen. Clin Exp Allergy 2005;35: 1421-2.

16. Spergel JM, Andrews T, Brown-Whitehorn TF, Beausoleil JL, Liacouras CA. Treatment of eosinophilic esophagitis with specific food elimination diet directed by a combination of skin prick and patch tests. Ann Allergy Asthma Immunol 2005;95:336-43.

17. Blanchard C, Wang N, Stringer KF, Mishra A, Fulkerson PC, Abonia JP, et al. Eotaxin-3 and a uniquely conserved gene-expression profile in eosinophilic esophagitis. J Clin Invest 2006;116:536-47.

18. Gupta SK, Fitzgerald JF, Kondratyuk T, HogenEsch H. Cytokine expression in normal and inflamed esophageal mucosa: a study into the pathogenesis of allergic eosinophilic esophagitis. J Pediatr Gastroenterol Nutr 2006;42:22-6.

19. Kagalwalla AF, Sentongo TA, Ritz S, Hess T, Nelson SP, Emerick KM, et al. Effect of six-food elimination diet on clinical and histologic outcomes in eosinophilic esophagitis. Clin Gastroenterol Hepatol 2006;4:1097-102.

20. Yamazaki K, Murray JA, Arora AS, Alexander JA, Smyrk TC, Butterfield JH, et al. Allergen-specific in vitro cytokine production in adult patients with eosinophilic esophagitis. Dig Dis Sci 2006;51:1934-41

21. Bhattacharya B, Carlsten J, Sabo E, Kethu S, Meitner P, Tavares R, et al. Increased expression of eotaxin-3 distinguishes between eosinophilic esophagitis and gastroesophageal reflux disease. Hum Pathol 2007;38:1744-53.

22. Blanchard C, Mingler MK, Vicario M, Abonia JP, Wu YY, Lu TX, et al. IL-13 involvement in eosinophilic esophagitis: transcriptome analysis and reversibility with glucocorticoids. J Allergy Clin Immunol 2007;120:1292-300.

23. Bullock JZ, Villanueva JM, Blanchard C, Filipovich AH, Putnam PE, Collins $\mathrm{MH}$, et al. Interplay of adaptive th2 immunity with eotaxin-3/c-C chemokine receptor 3 in eosinophilic esophagitis. J Pediatr Gastroenterol Nutr 2007;45: 22-31.

24. Kirsch R, Bokhary R, Marcon MA, Cutz E. Activated mucosal mast cells differentiate eosinophilic (allergic) esophagitis from gastroesophageal reflux disease J Pediatr Gastroenterol Nutr 2007;44:20-6.

25. Spergel JM, Brown-Whitehorn T, Beausoleil JL, Shuker M, Liacouras CA. Predictive values for skin prick test and atopy patch test for eosinophilic esophagitis. J Allergy Clin Immunol 2007;119:509-11.

26. Lucendo AJ, De Rezende L, Comas C, Caballero T, Bellon T. Treatment with topical steroids downregulates IL-5, eotaxin-1/CCL11, and eotaxin-3/CCL26 gene expression in eosinophilic esophagitis. Am J Gastroenterol 2008;103:2184-93. 
27. Mishra A, Wang M, Pemmaraju VR, Collins MH, Fulkerson PC, Abonia JP, et al. Esophageal remodeling develops as a consequence of tissue specific IL-5-induced eosinophilia. Gastroenterology 2008;134:204-14.

28. Rothenberg ME. Biology and treatment of eosinophilic esophagitis. Gastroenterology 2009;137:1238-49.

29. Tantibhaedhyangkul U, Tatevian N, Gilger MA, Major AM, Davis CM. Increased esophageal regulatory $\mathrm{T}$ cells and eosinophil characteristics in children with eosinophilic esophagitis and gastroesophageal reflux disease. Ann Clin Lab Sci 2009;39:99-107.

30. Zhu X, Wang M, Crump CH, Mishra A. An imbalance of esophageal effector and regulatory $\mathrm{T}$ cell subsets in experimental eosinophilic esophagitis in mice. Am J Physiol Gastrointest Liver Physiol 2009;297:G550-8.

31. Aceves SS, Chen D, Newbury RO, Dohil R, Bastian JF, Broide DH. Mast cells infiltrate the esophageal smooth muscle in patients with eosinophilic esophagitis, express TGF-beta1, and increase esophageal smooth muscle contraction. J Allergy Clin Immunol 2010;126:1198-204, e4.

32. Blanchard C, Stucke EM, Burwinkel K, Caldwell JM, Collins MH, Ahrens A, et al. Coordinate interaction between IL-13 and epithelial differentiation cluster genes in eosinophilic esophagitis. J Immunol 2010;184:4033-41.

33. Caldwell JM, Blanchard C, Collins MH, Putnam PE, Kaul A, Aceves SS, et al. Glucocorticoid-regulated genes in eosinophilic esophagitis: a role for FKBP51. J Allergy Clin Immunol 2010;125:879-88, e8.

34. Dellon ES, Chen X, Miller CR, Fritchie KJ, Rubinas TC, Woosley JT, et al. Tryptase staining of mast cells may differentiate eosinophilic esophagitis from gastroesophageal reflux disease. Am J Gastroenterol 2011;106:264-71.

35. Fuentebella J, Patel A, Nguyen T, Sanjanwala B, Berquist W, Kerner JA, et al. Increased number of regulatory $\mathrm{T}$ cells in children with eosinophilic esophagitis J Pediatr Gastroenterol Nutr 2010;51:283-9.

36. Neilsen CV, Bryce PJ. Interleukin-13 directly promotes oesophagus production of CCL11 and CCL24 and the migration of eosinophils. Clin Exp Allergy 2010;40: 427-34.

37. Patel AJ, Fuentebella J, Gernez Y, Nguyen T, Bass D, Berquist W, et al. Increased HLA-DR expression on tissue eosinophils in eosinophilic esophagitis. J Pediatr Gastroenterol Nutr 2010;51:290-4.

38. Rothenberg ME, Spergel JM, Sherrill JD, Annaiah K, Martin LJ, Cianferoni A, et al. Common variants at $5 \mathrm{q} 22$ associate with pediatric eosinophilic esophagitis Nat Genet 2010;42:289-91.

39. Sherrill JD, Gao PS, Stucke EM, Blanchard C, Collins MH, Putnam PE, et al Variants of thymic stromal lymphopoietin and its receptor associate with eosinophilic esophagitis. J Allergy Clin Immunol 2010;126:160-5, e3.

40. Straumann A, Conus S, Grzonka P, Kita H, Kephart G, Bussmann C, et al. Antiinterleukin-5 antibody treatment (mepolizumab) in active eosinophilic oesophagitis: a randomised, placebo-controlled, double-blind trial. Gut 2010;59:21-30.

41. Vicario M, Blanchard C, Stringer KF, Collins MH, Mingler MK, Ahrens A, et al. Local B cells and IgE production in the oesophageal mucosa in eosinophilic oesophagitis. Gut 2010;59:12-20.

42. Yen EH, Hornick JL, Dehlink E, Dokter M, Baker A, Fiebiger E, et al. Comparative analysis of FcepsilonRI expression patterns in patients with eosinophilic and reflux esophagitis. J Pediatr Gastroenterol Nutr 2010;51:584-92.

43. Zhu X, Wang M, Mavi P, Rayapudi M, Pandey AK, Kaul A, et al. Interleukin-15 expression is increased in human eosinophilic esophagitis and mediates pathogenesis in mice. Gastroenterology 2010;139:182-93, e7.

44. Zuo L, Fulkerson PC, Finkelman FD, Mingler M, Fischetti CA, Blanchard C, et al. IL13 induces esophageal remodeling and gene expression by an eosinophilindependent, IL-13R alpha2-inhibited pathway. J Immunol 2010;185:660-9.

45. Frischmeyer-Guerrerio PA, Guerrerio AL, Chichester KL, Bieneman AP, Hamilton RA, Wood RA, et al. Dendritic cell and T cell responses in children with food allergy. Clin Exp Allergy 2011;41:61-71.

46. Aceves SS, Newbury RO, Dohil MA, Bastian JF, Dohil R. A symptom scoring tool for identifying pediatric patients with eosinophilic esophagitis and correlating symptoms with inflammation. Ann Allergy Asthma Immunol 2009;103:401-6.

47. Mukkada VA, Haas A, Maune NC, Capocelli KE, Henry M, Gilman N, et al. Feeding dysfunction in children with eosinophilic gastrointestinal diseases. Pediatrics 2010;126:e672-7.

48. Garcia-Compean D, Gonzalez Gonzalez JA, Marrufo Garcia CA, Flores Gutierrez JP, Barboza Quintana O, Galindo Rodriguez G, et al. Prevalence of eosinophilic esophagitis in patients with refractory gastroesophageal reflux disease symptoms: a prospective study. Dig Liver Dis 2011;43:204-8.

49. Kapel RC, Miller JK, Torres C, Aksoy S, Lash R, Katzka DA. Eosinophilic esophagitis: a prevalent disease in the United States that affects all age groups. Gastroenterology 2008;134:1316-21.

50. Foroutan M, Norouzi A, Molaei M, Mirbagheri SA, Irvani S, Sadeghi A, et al Eosinophilic esophagitis in patients with refractory gastroesophageal reflux disease. Dig Dis Sci 2010;55:28-31.
51. Lai AL, Girgis S, Liang Y, Carr S, Huynh HQ. Diagnostic criteria for eosinophilic esophagitis: a 5-year retrospective review in a pediatric population. J Pediatr Gastroenterol Nutr 2009;49:63-70.

52. Ronkainen J, Talley NJ, Aro P, Storskrubb T, Johansson SE, Lind T, et al. Prevalence of oesophageal eosinophils and eosinophilic oesophagitis in adults: the population-based Kalixanda study. Gut 2007;56:615-20.

53. Prasad GA, Alexander JA, Schleck CD, Zinsmeister AR, Smyrk TC, Elias RM, et al. Epidemiology of eosinophilic esophagitis over three decades in Olmsted County, Minnesota. Clin Gastroenterol Hepatol 2009;7:1055-61.

54. Dalby K, Nielsen RG, Kruse-Andersen S, Fenger C, Bindslev-Jensen C, Ljungberg S, et al. Eosinophilic oesophagitis in infants and children in the region of southern Denmark: a prospective study of prevalence and clinical presentation. J Pediatr Gastroenterol Nutr 2010;51:280-2.

55. Bove M, Tegtmeyer B, Persson S, Bergquist $\mathrm{H}$. The pharyngeal mucosa is not involved in eosinophilic oesophagitis. Aliment Pharmacol Ther 2009;30: 495-500.

56. Mackenzie SH, Go M, Chadwick B, Thomas K, Fang J, Kuwada S, et al. Eosinophilic oesophagitis in patients presenting with dysphagia—a prospective analysis. Aliment Pharmacol Ther 2008;28:1140-6.

57. Prasad GA, Talley NJ, Romero Y, Arora AS, Kryzer LA, Smyrk TC, et al. Prevalence and predictive factors of eosinophilic esophagitis in patients presenting with dysphagia: a prospective study. Am J Gastroenterol 2007;102:2627-32.

58. Poh CH, Gasiorowska A, Navarro-Rodriguez T, Willis MR, Hargadon D, Noelck $\mathrm{N}$, et al. Upper GI tract findings in patients with heartburn in whom proton pump inhibitor treatment failed versus those not receiving antireflux treatment. Gastrointest Endosc 2010;71:28-34.

59. Krarup AL, Villadsen GE, Mejlgaard E, Olesen SS, Drewes AM, Funch-Jensen P. Acid hypersensitivity in patients with eosinophilic oesophagitis. Scand J Gastroenterol 2010;45:273-81.

60. Straumann A. The natural history and complications of eosinophilic esophagitis. Gastrointest Endosc Clin N Am 2008;18:99-118, ix.

61. Desai TK, Stecevic V, Chang CH, Goldstein NS, Badizadegan K, Furuta GT. Association of eosinophilic inflammation with esophageal food impaction in adults. Gastrointest Endosc 2005;61:795-801.

62. Peterson KA, Thomas KL, Hilden K, Emerson LL, Wills JC, Fang JC. Comparison of esomeprazole to aerosolized, swallowed fluticasone for eosinophilic esophagitis. Dig Dis Sci 2010;55:1313-9.

63. Sayej WN, Patel R, Baker RD, Tron E, Baker SS. Treatment with high-dose proton pump inhibitors helps distinguish eosinophilic esophagitis from noneosinophilic esophagitis. J Pediatr Gastroenterol Nutr 2009;49:393-9.

64. Kedika RR, Souza RF, Spechler SJ. Potential anti-inflammatory effects of proton pump inhibitors: a review and discussion of the clinical implications. Dig Dis Sci 2009;54:2312-7.

65. Merwat SN, Spechler SJ. Might the use of acid-suppressive medications predispose to the development of eosinophilic esophagitis? Am J Gastroenterol 2009; 104:1897-902.

66. Schlesinger PK, Donahue PE, Schmid B, Layden TJ. Limitations of 24-hour intraesophageal $\mathrm{pH}$ monitoring in the hospital setting. Gastroenterology 1985;89: 797-804.

67. Murphy DW, Yuan Y, Castell DO. Does the intraesophageal $\mathrm{pH}$ probe accurately detect acid reflux? Simultaneous recording with two $\mathrm{pH}$ probes in humans. Dig Dis Sci 1989;34:649-56.

68. Aceves SS, Ackerman SJ. Relationships between eosinophilic inflammation, tissue remodeling, and fibrosis in eosinophilic esophagitis. Immunol Allergy Clin North Am 2009;29:197-211, xiii-xiv.

69. Aceves SS, Newbury RO, Chen D, Mueller J, Dohil R, Hoffman H, et al. Resolution of remodeling in eosinophilic esophagitis correlates with epithelial response to topical corticosteroids. Allergy 2010;65:109-16.

70. Pentiuk S, Putnam PE, Collins MH, Rothenberg ME. Dissociation between symptoms and histological severity in pediatric eosinophilic esophagitis. J Pediatr Gastroenterol Nutr 2009;48:152-60.

71. Schoepfer AM, Gonsalves N, Bussmann C, Conus S, Simon HU, Straumann A, et al. Esophageal dilation in eosinophilic esophagitis: effectiveness, safety, and impact on the underlying inflammation. Am J Gastroenterol 2010;105: 1062-70.

72. Baxi S, Gupta SK, Swigonski N, Fitzgerald JF. Clinical presentation of patients with eosinophilic inflammation of the esophagus. Gastrointest Endosc 2006;64: 473-8.

73. Shah A, Kagalwalla AF, Gonsalves N, Melin-Aldana H, Li BU, Hirano I. Histopathologic Variability in Children With Eosinophilic Esophagitis. Am J Gastroenterol 2009;104:716-21

74. Yantiss RK, Odze RD. Optimal approach to obtaining mucosal biopsies for assessment of inflammatory disorders of the gastrointestinal tract. Am J Gastroenterol 2009;104:774-83. 
75. Binkovitz LA, Lorenz EA, Di Lorenzo C, Kahwash S. Pediatric eosinophilic esophagitis: radiologic findings with pathologic correlation. Pediatr Radiol 2010;40:714-9.

76. DeBrosse CW, Collins MH, Buckmeier Butz BK, Allen CL, King EC, Assa'ad $\mathrm{AH}$, et al. Identification, epidemiology, and chronicity of pediatric esophageal eosinophilia, 1982-1999. J Allergy Clin Immunol 2010;126:112-9.

77. Aceves SS, Newbury RO, Dohil R, Schwimmer J, Bastian JF. Distinguishing eosinophilic esophagitis in pediatric patients: clinical, endoscopic, and histologic features of an emerging disorder. J Clin Gastroenterol 2007;41:252-6.

78. Lee S, de Boer WB, Naran A, Leslie C, Raftopoulous S, Ee H, et al. More than just counting eosinophils: proximal oesophageal involvement and subepithelial sclerosis are major diagnostic criteria for eosinophilic oesophagitis. J Clin Pathol 2010;63:644-7.

79. Liacouras CA, Spergel JM, Ruchelli E, Verma R, Mascarenhas M, Semeao E, et al. Eosinophilic esophagitis: a 10-year experience in 381 children. Clin Gastroenterol Hepatol 2005;3:1198-206.

80. Kephart GM, Alexander JA, Arora AS, Romero Y, Smyrk TC, Talley NJ, et al. Marked deposition of eosinophil-derived neurotoxin in adult patients with eosinophilic esophagitis. Am J Gastroenterol 2010;105:298-307.

81. Mueller S, Neureiter D, Aigner T, Stolte M. Comparison of histological parameters for the diagnosis of eosinophilic oesophagitis versus gastrooesophageal reflux disease on oesophageal biopsy material. Histopathology 2008;53:676-84.

82. Protheroe C, Woodruff SA, de Petris G, Mukkada V, Ochkur SI, Janarthanan S, et al. A novel histologic scoring system to evaluate mucosal biopsies from patients with eosinophilic esophagitis. Clin Gastroenterol Hepatol 2009;7:749-55, e11.

83. Dellon ES, Aderoju A, Woosley JT, Sandler RS, Shaheen NJ. Variability in diagnostic criteria for eosinophilic esophagitis: a systematic review. Am J Gastroenterol 2007;102:2300-13.

84. Aceves SS, Newbury RO, Dohil R, Bastian JF, Broide DH. Esophageal remodeling in pediatric eosinophilic esophagitis. J Allergy Clin Immunol 2007;119:206-12.

85. Chehade M, Sampson HA, Morotti RA, Magid MS. Esophageal subepithelial fibrosis in children with eosinophilic esophagitis. J Pediatr Gastroenterol Nutr 2007;45:319-28.

86. Genevay M, Rubbia-Brandt L, Rougemont AL. Do eosinophil numbers differentiate eosinophilic esophagitis from gastroesophageal reflux disease? Arch Pathol Lab Med 2010;134:815-25.

87. Steiner SJ, Kernek KM, Fitzgerald JF. Severity of basal cell hyperplasia differs in reflux versus eosinophilic esophagitis. J Pediatr Gastroenterol Nutr 2006;42: 506-9.

88. Lucendo AJ, Bellon T, Lucendo B. The role of mast cells in eosinophilic esophagitis. Pediatr Allergy Immunol 2009;20:512-8.

89. Mishra A. Mechanism of eosinophilic esophagitis. Immunol Allergy Clin North Am 2009;29:29-40, viii.

90. Blanchard C, Mingler MK, McBride M, Putnam PE, Collins MH, Chang G, et al. Periostin facilitates eosinophil tissue infiltration in allergic lung and esophageal responses. Mucosal Immunol 2008;1:289-96.

91. Bhattacharya B, Carlsten J, Sabo E, Kethu S, Meitner P, Tavares R, et al. Increased expression of eotaxin-3 distinguishes between eosinophilic esophagitis and gastroesophageal reflux disease. Hum Pathol 2007;38:1744-53.

92. Lucendo AJ, Navarro M, Comas C, Pascual JM, Burgos E, Santamaria L, et al. Immunophenotypic characterization and quantification of the epithelial inflammatory infiltrate in eosinophilic esophagitis through stereology: an analysis of the cellular mechanisms of the disease and the immunologic capacity of the esophagus. Am J Surg Pathol 2007;31:598-606.

93. Mulder DJ, Pacheco I, Hurlbut DJ, Mak N, Furuta GT, MacLeod RJ, et al. FGF9induced proliferative response to eosinophilic inflammation in oesophagitis. Gut 2009;58:166-73

94. Rogart JN, Nagata J, Loeser CS, Roorda RD, Aslanian H, Robert ME, et al. Multiphoton imaging can be used for microscopic examination of intact human gastrointestinal mucosa ex vivo. Clin Gastroenterol Hepatol 2008;6:95-101.

95. Rubio CA, Glaessgen A. An improved method to visualize eosinophils in eosinophilic esophagitis. In Vivo 2006;20:681-5.

96. Savarino E, Tutuian R, Zentilin P, Dulbecco P, Pohl D, Marabotto E, et al. Characteristics of reflux episodes and symptom association in patients with erosive esophagitis and nonerosive reflux disease: study using combined impedance-pH off therapy. Am J Gastroenterol 2010;105:1053-61.

97. Dalby K, Nielsen RG, Kruse-Andersen S, Fenger C, Durup J, Husby S. Gastroesophageal reflux disease and eosinophilic esophagitis in infants and children. A study of esophageal $\mathrm{pH}$, multiple intraluminal impedance and endoscopic ultrasound. Scand J Gastroenterol 2010;45:1029-35.

98. Rosen R, Furuta G, Fritz J, Donovan K, Nurko S. Role of acid and nonacid reflux in children with eosinophilic esophagitis compared with patients with gastroesophageal reflux and control patients. J Pediatr Gastroenterol Nutr 2008;46:520-3.
99. Korsapati H, Babaei A, Bhargava V, Dohil R, Quin A, Mittal RK. Dysfunction of the longitudinal muscles of the oesophagus in eosinophilic oesophagitis. Gut 2009;58:1056-62.

100. Nurko S, Rosen R, Furuta GT. Esophageal dysmotility in children with eosinophilic esophagitis: a study using prolonged esophageal manometry. Am J Gastroenterol 2009;104:3050-7.

101. Roman S, Hirano I, Kwiatek MA, Gonsalves N, Chen J, Kahrilas PJ, et al. Manometric features of eosinophilic esophagitis in esophageal pressure topography. Neurogastroenterol Motil 2011;23:208-e111.

102. Kwiatek MA, Hirano I, Kahrilas PJ, Rothe J, Luger D, Pandolfino JE. Mechanical properties of the esophagus in eosinophilic esophagitis. Gastroenterology 2011; 140:82-90.

103. Blanchard C, Wang N, Stringer KF, Mishra A, Fulkerson PC, Abonia JP, et al. Eotaxin-3 and a uniquely conserved gene-expression profile in eosinophilic esophagitis. J Clin Invest 2006;116:536-47.

104. Zuo L, Fulkerson PC, Finkelman FD, Mingler M, Fischetti CA, Blanchard C, et al. IL-13 induces esophageal remodeling and gene expression by an eosinophil-independent, IL-13R alpha 2-inhibited pathway. J Immunol 2010; 185:660-9.

105. Abonia JP, Blanchard C, Butz BB, Rainey HF, Collins MH, Stringer K, et al. Involvement of mast cells in eosinophilic esophagitis. J Allergy Clin Immunol 2010, 126:140-9.

106. Blanchard C, Wang N, Rothenberg ME. Eosinophilic esophagitis: pathogenesis, genetics, and therapy. J Allergy Clin Immunol 2006;118:1054-9.

107. Almansa C, Krishna M, Buchner AM, Ghabril MS, Talley N, DeVault KR, et al. Seasonal distribution in newly diagnosed cases of eosinophilic esophagitis in adults. Am J Gastroenterol 2009;104:828-33.

108. Moawad FJ, Veerappan GR, Lake JM, Maydonovitch CL, Haymore BR, Kosisky SE, et al. Correlation between eosinophilic oesophagitis and aeroallergens. Aliment Pharmacol Ther 2010;31:509-15.

109. Roy-Ghanta S, Larosa DF, Katzka DA. Atopic characteristics of adult patients with eosinophilic esophagitis. Clin Gastroenterol Hepatol 2008;6:531-5.

110. Spergel JM, Brown-Whitehorn TF, Beausoleil JL, Franciosi J, Shuker M, Verma $\mathrm{R}$, et al. 14 years of eosinophilic esophagitis: clinical features and prognosis. J Pediatr Gastroenterol Nutr 2009;48:30-6.

111. Erwin EA, James HR, Gutekunst HM, Russo JM, Kelleher KJ, Platts-Mills TA. Serum IgE measurement and detection of food allergy in pediatric patients with eosinophilic esophagitis. Ann Allergy Asthma Immunol 2010;104:496-502.

112. Dohil R, Newbury R, Fox L, Bastian J, Aceves S. Oral viscous budesonide is effective in children with eosinophilic esophagitis in a randomized, placebocontrolled trial. Gastroenterology 2010;139:418-29.

113. Chehade M. IgE and non-IgE-mediated food allergy: treatment in 2007. Curr Opin Allergy Clin Immunol 2007;7:264-8.

114. Sugnanam KK, Collins JT, Smith PK, Connor F, Lewindon P, Cleghorn G, et al. Dichotomy of food and inhalant allergen sensitization in eosinophilic esophagitis. Allergy 2007;62:1257-60.

115. Veerappan GR, Perry JL, Duncan TJ, Baker TP, Maydonovitch C, Lake JM, et al. Prevalence of eosinophilic esophagitis in an adult population undergoing upper endoscopy: a prospective study. Clin Gastroenterol Hepatol 2009;7:420-6, e1-2.

116. Wang FY, Gupta SK, Fitzgerald JF. Is there a seasonal variation in the incidence or intensity of allergic eosinophilic esophagitis in newly diagnosed children? J Clin Gastroenterol 2007;41:451-3.

117. Mishra A, Hogan SP, Brandt EB, Rothenberg ME. An etiological role for aeroallergens and eosinophils in experimental esophagitis. J Clin Invest 2001;107: 83-90.

118. Rayapudi M, Mavi P, Zhu X, Pandey AK, Abonia JP, Rothenberg ME, et al. Indoor insect allergens are potent inducers of experimental eosinophilic esophagitis in mice. J Leukoc Biol 2010;88:337-46.

119. Chehade M, Sampson HA. Epidemiology and etiology of eosinophilic esophagitis. Gastrointest Endosc Clin N Am 2008;18:33-44, viii.

120. Straumann A, Conus S, Degen L, Felder S, Kummer M, Engel H, et al. Budesonide is effective in adolescent and adult patients with active eosinophilic esophagitis. Gastroenterology 2010;139:1526-37, e1.

121. Patel AJ, Fuentebella J, Gernez Y, Nguyen T, Bass D, Berquist W, et al. Increased HLA-DR expression on tissue eosinophils in eosinophilic esophagitis. J Pediatr Gastroenterol Nutr 2010;51:290-4.

122. Huang JJ, Joh JW, Fuentebella J, Patel A, Nguyen T, Seki S, et al. Eotaxin and FGF enhance signaling through an extracellular signal-related kinase (ERK)dependent pathway in the pathogenesis of eosinophilic esophagitis. Allergy Asthma Clin Immunol 2010;6:25

123. Prussin C, Lee J, Foster B. Eosinophilic gastrointestinal disease and peanut allergy are alternatively associated with IL-5+ and IL-5(-) $\mathrm{T}(\mathrm{H}) 2$ responses J Allergy Clin Immunol 2009;124:1326-32, e6. 
124. Collins MH, Blanchard C, Abonia JP, Kirby C, Akers R, Wang N, et al. Clinical, pathologic, and molecular characterization of familial eosinophilic esophagitis compared with sporadic cases. Clin Gastroenterol Hepatol 2008;6:621-9.

125. Penfield JD, Lang DM, Goldblum JR, Lopez R, Falk GW. The role of allergy evaluation in adults with eosinophilic esophagitis. J Clin Gastroenterol 2010 44:22-7.

126. Dalby K, Nielsen RG, Kruse-Andersen S, Fenger C, Bindslev-Jensen C, Ljungberg $\mathrm{S}$, et al. Eosinophilic oesophagitis in infants and children in the region of southern Denmark: a prospective study of prevalence and clinical presentation. J Pediatr Gastroenterol Nutr 2010;51:280-2.

127. Castellano Mdel R, Cimbollek S, Quiralte J. Defining the role of food allergy in a population of adult patients with eosinophilic esophagitis. Inflamm Allergy Drug Targets 2010;9:257-62.

128. Barbi E, Gerarduzzi T, Longo G, Ventura A. Fatal allergy as a possible consequence of long-term elimination diet. Allergy 2004;59:668-9.

129. Flinterman AE, Knulst AC, Meijer Y, Bruijnzeel-Koomen CA, Pasmans SG. Acute allergic reactions in children with AEDS after prolonged cow's milk elimination diets. Allergy 2006;61:370-4.

130. Boyce JA, Assa'ad A, Burks AW, Jones SM, Sampson HA, Wood RA, et al. Guidelines for the diagnosis and management of food allergy in the United States: report of the NIAID-sponsored expert panel. J Allergy Clin Immunol 2010; 126(suppl):S1-58.

131. Boyce JA, Assa'ad A, Burks AW, Jones SM, Sampson HA, Wood RA, et al Guidelines for the diagnosis and management of food allergy in the United States: summary of the NIAID-sponsored expert panel report. J Allergy Clin Immunol 2010;126:1105-18.

132. Dellon ES, Farrell TM, Bozymski EM, Shaheen NJ. Diagnosis of eosinophilic esophagitis after fundoplication for "refractory reflux": implications for preoperative evaluation. Dis Esophagus 2010;23:191-5.

133. Sayej WN, Patel R, Baker RD, Tron E, Baker SS. Treatment with high-dose proton pump inhibitors helps distinguish eosinophilic esophagitis from noneosinophilic esophagitis. J Pediatr Gastroenterol Nutr 2009;49:393-9.

134. Dranove JE, Horn DS, Davis MA, Kernek KM, Gupta SK. Predictors of response to proton pump inhibitor therapy among children with significant esophageal eosinophilia. J Pediatr 2009;154:96-100.

135. Spergel JM. Eosinophilic esophagitis in adults and children: evidence for a food allergy component in many patients. Curr Opin Allergy Clin Immunol 2007; 274-8.

136. Abu-Sultaneh SM, Durst P, Maynard V, Elitsur Y. Fluticasone and food allergen elimination reverse sub-epithelial fibrosis in children with eosinophilic esophagitis. Dig Dis Sci 2011;56:97-102.

137. Chehade M, Aceves SS. Food allergy and eosinophilic esophagitis. Curr Opin Allergy Clin Immunol 2010;10:231-7.

138. Konikoff MR, Noel RJ, Blanchard C, Kirby C, Jameson SC, Buckmeier BK, et al A randomized, double-blind, placebo-controlled trial of fluticasone propionate for pediatric eosinophilic esophagitis. Gastroenterology 2006;131:1381-91.

139. Helou EF, Simonson J, Arora AS. 3-yr-follow-up of topical corticosteroid treatment for eosinophilic esophagitis in adults. Am J Gastroenterol 2008;103 2194-9.

140. Schaefer ET, Fitzgerald JF, Molleston JP, Croffie JM, Pfefferkorn MD, Corkins $\mathrm{MR}$, et al. Comparison of oral prednisone and topical fluticasone in the treatment of eosinophilic esophagitis: a randomized trial in children. Clin Gastroenterol Hepatol 2008;6:165-73

141. Gupta SK, Peters-Golden M, Fitzgerald JF, Croffie JM, Pfefferkorn MD, Molleston JP, et al. Cysteinyl leukotriene levels in esophageal mucosal biopsies of children with eosinophilic inflammation: are they all the same? Am J Gastroenterol 2006; 101:1125-8

142. Straumann A, Bussmann C, Conus S, Beglinger C, Simon HU. Anti-TNF-alpha (infliximab) therapy for severe adult eosinophilic esophagitis. J Allergy Clin Immunol 2008;122:425-7.

143. Stein ML, Collins MH, Villanueva JM, Kushner JP, Putnam PE, Buckmeier BK, et al. Anti-IL-5 (mepolizumab) therapy for eosinophilic esophagitis. J Allergy Clin Immunol 2006;118:1312-9.

144. Netzer P, Gschossmann JM, Straumann A, Sendensky A, Weimann R, Schoepfer AM. Corticosteroid-dependent eosinophilic oesophagitis: azathioprine and 6-mercaptopurine can induce and maintain long-term remission. Eur J Gastroenterol Hepatol 2007;19:865-9.

145. Gonsalves N, Policarpio-Nicolas M, Zhang Q, Rao MS, Hirano I. Histopathologic variability and endoscopic correlates in adults with eosinophilic esophagitis. Gastrointest Endosc 2006;64:313-9.
146. Straumann A, Bussmann C, Zuber M, Vannini S, Simon HU, Schoepfer A. Eosinophilic esophagitis: analysis of food impaction and perforation in 251 adolescent and adult patients. Clin Gastroenterol Hepatol 2008;6:598-600.

147. Byrne KR, Panagiotakis PH, Hilden K, Thomas KL, Peterson KA, Fang JC. Retrospective analysis of esophageal food impaction: differences in etiology by age and gender. Dig Dis Sci 2007;52:717-21.

148. Kerlin P, Jones D, Remedios M, Campbell C. Prevalence of eosinophilic esophagitis in adults with food bolus obstruction of the esophagus. J Clin Gastroenterol 2007;41:356-61.

149. Bohm M, Richter JE, Kelsen S, Thomas R. Esophageal dilation: simple and effective treatment for adults with eosinophilic esophagitis and esophageal rings and narrowing. Dis Esophagus 2010;23:377-85

150. Kanakala V, Lamb CA, Haigh C, Stirling RW, Attwood SE. The diagnosis of primary eosinophilic oesophagitis in adults: missed or misinterpreted? Eur J Gastroenterol Hepatol 2010;22:848-55.

151. Lucendo AJ, De Rezende L. Endoscopic dilation in eosinophilic esophagitis: a treatment strategy associated with a high risk of perforation. Endoscopy 2007; 39:376-7.

152. Cohen MS, Kaufman AB, Palazzo JP, Nevin D, Dimarino AJ Jr, Cohen S. An audit of endoscopic complications in adult eosinophilic esophagitis. Clin Gastroenterol Hepatol 2007;5:1149-53.

153. Riou PJ, Nicholson AG, Pastorino U. Esophageal rupture in a patient with idiopathic eosinophilic esophagitis. Ann Thorac Surg 1996;62:1854-6.

154. Spahn TW, Vieth M, Mueller MK. Paracetamol-induced perforation of the esophagus in a patient with eosinophilic esophagitis. Endoscopy 2010;42(suppl 2):E31-2.

155. Robles-Medranda C, Villard F, Bouvier R, Dumortier J, Lachaux A. Spontaneous esophageal perforation in eosinophilic esophagitis in children. Endoscopy 2008; 40(suppl 2):E171.

156. Giles H, Smith L, Tolosa D, Miranda MJ, Laman D. Eosinophilic esophagitis: a rare cause of esophageal rupture in children. Am Surg 2008;74:750-2.

157. Gomez Senent S, Adan Merino L, Froilan Torres C, Plaza Santos R, Suarez de Parga JM. [Spontaneous esophageal rupture as onset of eosinophilic esophagitis]. Gastroenterol Hepatol 2008;31:50-1.

158. Liguori G, Cortale M, Cimino F, Sozzi M. Circumferential mucosal dissection and esophageal perforation in a patient with eosinophilic esophagitis. World $\mathrm{J}$ Gastroenterol 2008;14:803-4.

159. Quiroga J, Prim JM, Moldes M, Ledo R. Spontaneous circumferential esophageal dissection in a young man with eosinophilic esophagitis. Interact Cardiovasc Thorac Surg 2009;9:1040-2.

160. Shim LS, Grehan M. Education and imaging. Gastrointestinal: oesophageal perforation during endoscopy for food impaction in eosinophilic oesophagitis. J Gastroenterol Hepatol 2010;25:428

161. Nantes O, Jimenez FJ, Zozaya JM, Vila JJ. Increased risk of esophageal perforation in eosinophilic esophagitis. Endoscopy 2009;41(suppl 2):E177-8.

162. Kaplan M, Mutlu EA, Jakate S, Bruninga K, Losurdo J, Keshavarzian A. Endoscopy in eosinophilic esophagitis: "feline" esophagus and perforation risk. Clin Gastroenterol Hepatol 2003;1:433-7.

163. Arora AS, Perrault J, Smyrk TC. Topical corticosteroid treatment of dysphagia due to eosinophilic esophagitis in adults. Mayo Clin Proc 2003;78:830-5.

164. Wolfsen HC, Hemminger LL, Achem SR. Eosinophilic esophagitis and Barrett's esophagus with dysplasia. Clin Gastroenterol Hepatol 2007;5:A18.

165. Francalanci P, De Angelis P, Minnei F, Diomedi Camassei F, Torroni F, Dall'Oglio L, et al. Eosinophilic esophagitis and Barrett's esophagus: an occasional association or an overlap disease? Esophageal "double trouble" in two children. Digestion 2008;77:16-9.

166. Morrow JB, Vargo JJ, Goldblum JR, Richter JE. The ringed esophagus: histological features of GERD. Am J Gastroenterol 2001;96:984-9.

167. Mukkada V, Atkins D, Furuta GT. Uncertain association of Barrett's esophagus with eosinophilic esophagitis. Clin Gastroenterol Hepatol 2008;6:832-3.

168. Hirano I. Dilation in eosinophilic esophagitis: to do or not to do? Gastrointest Endosc 2010;71:713-4

169. Jung KW, Gundersen N, Kopacova J, Arora AS, Romero Y, Katzka D, et al. Occurrence of and risk factors for complications after endoscopic dilation in eosinophilic esophagitis. Gastrointest Endosc 2011;73:15-21.

170. Dellon ES, Gibbs WB, Rubinas TC, Fritchie KJ, Madanick RD, Woosley JT, et al. Esophageal dilation in eosinophilic esophagitis: safety and predictors of clinical response and complications. Gastrointest Endosc 2010;71:706-12.

171. Jung YM, Lee HS, Lee DH, Jeong YJ, Choi TH, Lee SH, et al. [Clinical significance of incidentally detected eosinophilic esophagitis with pathologic review]. Korean J Gastroenterol 2010;55:162-8. 


\section{APPENDIX E1. SUBCOMMITTEE PARTICIPANTS Definition and diagnostic guidelines}

Chair: Glenn T. Furuta, MD; Professor of Pediatrics; Director, Gastrointestinal Eosinophilic Diseases Program; Section of Pediatric Gastroenterology, Hepatology and Nutrition; The Children's Hospital of Denver, National Jewish Health; University of Colorado Denver School of Medicine, Aurora and Denver, Colorado

Richard J. Noel, MD; Assistant Professor of Pediatrics; Division of Pediatric Gastroenterology; Medical College of Wisconsin, Milwaukee, Wisconsin

Philip E. Putnam, MD, FAAP; Professor of Pediatrics; Division of Pediatric Gastroenterology, Hepatology, and Nutrition; Cincinnati Children's Hospital Medical Center; University of Cincinnati College of Medicine, Cincinnati, Ohio

Yvonne Romero, MD; Assistant Professor of Medicine; Division of Gastroenterology \& Hepatology and the Department of Otolaryngology; Mayo Clinic, Rochester, Minnesota

Eduardo Ruchelli, MD; Associate Professor of Pathology and Laboratory Medicine; Department of Pathology; The Children's Hospital of Philadelphia; University of Pennsylvania School of Medicine, Philadelphia, Pennsylvania

Stuart Spechler, MD; Professor of Medicine, Berta M. and Cecil O. Patterson Chair in Gastroenterology; Division of Gastroenterology; VA North Texas Healthcare System; University of Texas Southwestern Medical Center, Dallas, Texas

Alex Straumann, MD; Department of Gastroenterology; University Hospital of Basel; University of Basel School of Medicine, Basel, Switzerland

\section{Genotype and phenotype}

Chair: Marc E. Rothenberg, MD, PhD; Division of Allergy and Immunology; Director, Cincinnati Center for Eosinophilic Disorders; Professor of Pediatrics; Cincinnati Children's Hospital Medical Center; University of Cincinnati College of Medicine, Cincinnati Ohio

Margaret H. Collins, MD; Professor of Pathology; Division of Pathology; Cincinnati Children's Hospital Medical Center; University of Cincinnati College of Medicine, Cincinnati, Ohio

Evan S. Dellon, MD, MPH; Assistant Professor of Medicine; Center for Esophageal Disease and Swallowing; Division of Gastroenterology and Hepatology; UNC Hospitals; University of North Carolina School of Medicine, Chapel Hill, North Carolina

Robert D. Odze MD, FRCP; Professor of Pathology; Chief, GI Pathology Service; Brigham and Women's Hospital; Harvard Medical School, Boston, Massachusetts

Barry K. Wershil, MD; Chief, Division of Pediatric Gastroenterology, Hepatology, and Nutrition; Children's Memorial Hospital; University of Chicago, Chicago, Illinois

\section{Allergic evaluation}

Chair: Seema S. Aceves, MD, PhD; Assistant Professor of Pediatrics and Medicine; Director, Eosinophilic Gastrointestinal Disorders Clinic; Division of Allergy and Immunology; Rady Children's Hospital; University of California, San Diego, San Diego, California

Dan Atkins, MD; Professor of Pediatrics; Head, Division of Ambulatory Pediatrics; Co-Director Gastrointestinal Eosinophilic Diseases Program; National Jewish Health; University of Colorado Medical School, Denver, Colorado
A. Wesley Burks, MD; Professor and Chief, Pediatric Allergy and Immunology; Duke University Hospital; Duke; University Medical Center, Durham, North Carolina

Hugh A. Sampson, MD; Professor of Pediatrics; Dean for Translational Biomedical Sciences ; Division of Pediatric Allergy and Immunology; Mount Sinai Hospital; Mount Sinai School of Medicine, New York, New York

Scott H. Sicherer, MD; Professor of Pediatrics; Chief, Division of Pediatric Allergy and Immunology; Mount Sinai Hospital; Mount Sinai School of Medicine, New York, New York

Jonathan M. Spergel, MD, PhD; Associate Professor of Pediatrics; Chief, Allergy Section; Co-Director, Center for Pediatric Eosinophilic Disorders; Division of Allergy and Immunology; The Children's Hospital of Philadelphia; University of Pennsylvania School of Medicine, Philadelphia, Pennsylvania

\section{Dietary and medical treatment}

Chair: Chris A. Liacouras, MD; Professor of Pediatrics; CoDirector, Center for Pediatric Eosinophilic Disorders; Division of Gastroenterology, Hepatology, and Nutrition; The Children's Hospital of Philadelphia; University of Pennsylvania School of Medicine, Philadelphia, Pennsylvania

Peter A. Bonis, MD; Associate Professor of Medicine; Division of Gastroenterology; Tufts Medical Center; Tufts University School of Medicine, Boston, Massachusetts

Mirna Chehade, MD; Assistant Professor of Pediatrics; Mount Sinai Center for Eosinophilic Disorders; Division of Gastroenterology; Mount Sinai Hospital-Jaffe Food Allergy Institute; Mount Sinai School of Medicine, New York, New York

Ranjan Dohil, MD; Professor of Pediatrics; Division of Pediatric Gastroenterology and Hepatology; Rady Children's Hospital; San Diego University of California, San Diego, California

Nirmala Gonsalves, MD; Assistant Professor of Medicine; Division of Gastroenterology; Northwestern University Hospital; Northwestern University-Feinberg School of Medicine, Chicago, Illinois

Sandeep K. Gupta, MD; Professor of Clinical Pediatrics and Clinical Medicine,Co-Director, Center for Eosinophilic Diseases; Division of Pediatric Gastroenterology, Hepatology, and Nutrition; Riley Hospital for Children; Indiana University School of Medicine, Indianapolis, Indiana

David A. Katzka, MD; Professor of Medicine; Division of Gastroenterology and Hepatology; Mayo Clinic, Rochester, Minnesota

Alfredo J. Lucendo, MD, PhD; Department of Gastroenterology; Hospital General de Tomelloso, Tomelloso, Spain

Jonathan E. Markowitz, MD, MSCE; Pediatric Gastroenterology and Nutrition; Greenville Hospital System University Medical Center, Greenville, South Carolina

\section{Dilation and complications}

Chair: Ikuo Hirano, MD; Professor of Medicine; Division of Gastroenterology; Northwestern University Feinberg School of Medicine, Chicago, Illinois

Stephen E. Attwood, MD, FRCS, FRCSI, MCh; Senior Lecturer in Surgery and Consultant Surgeon, Northumbria Healthcare Department of Surgery; North Tyneside Hospital; Newcastle University, North Shields, Tyne + Wear, United Kingdom 
Gary W. Falk, MD, MS; Professor of Medicine; Division of Gastroenterology; Hospital of the University of Pennsylvania; University of Pennsylvania School of Medicine, Philadelphia, Pennsylvania

Joel E. Richter, MD, FACP, MACG; Professor and Chair; Department of Medicine; Temple University Hospital; Temple University Department of Medicine, Philadelphia, Pennsylvania
Alain Schoepfer, MD; Department of Gastroenterology and Hepatology; University Hospital Lausanne, Lausanne, Switzerland

Nicholas J. Shaheen, MD, MPH; Professor of Medicine and Epidemiology; Director, Center for Esophageal Diseases and Swallowing; Division of Gastroenterology; UNC Hospitals; University of North Carolina School of Medicine, Chapel Hill, North Carolina 


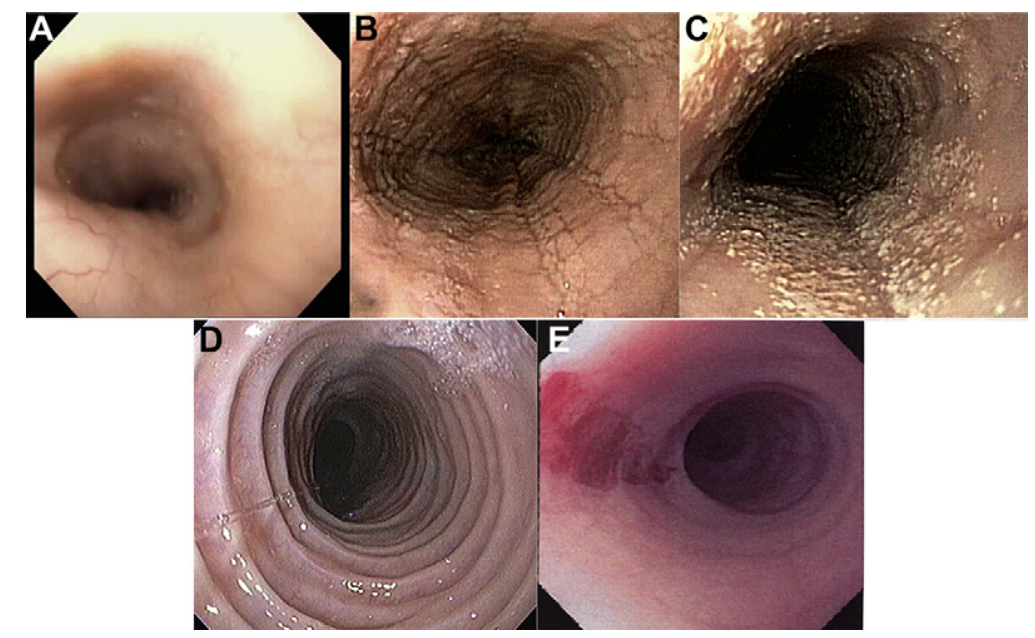

FIG E1. Endoscopic features of EoE. A, Normal esophagus. B, Esophageal furrowing. C, White mucosal plaques. D, Esophageal ring trachealization. E, Small-caliber esophagus with mucosal tearing after endoscopy. 
Dysphagia and feeding dysfunction

Coping mechanisms: avoiding highly textured foods, such as meats, and bulky foods, such as bagels; cutting food in small pieces; lubricating foods before eating with liquids or butter; extensive chewing of foods; washing food down with liquids; prolongation of mealtimes

Food impaction

Coping mechanisms: drinking liquid to wash food down, raising hands above head, jumping up and down, waiting for food to dissolve or to pass into stomach

Chest pain

Coping mechanisms: avoiding foods or liquids that exacerbate pain, such as highly textured or bulky foods, alcohol, or acidic drinks GERD-like symptoms recalcitrant to medical and surgical GERD management

Abdominal pain

Vomiting

Anorexia and early satiety 
TABLE E2. Endoscopic and radiologic features of EoE

Isolated stricture (proximal or distal)

Longitudinal narrowing (small or narrow-caliber esophagus)

Longitudinal shearing (crepe paper esophagus)

White exudates

Linear furrows or vertical lines

Fixed esophageal rings (corrugated rings or trachealization)

Transient esophageal rings (feline folds or felinization) 


\section{TABLE E3. Histologic features of EoE}

Mucosal eosinophilia

Eosinophil microabscess formation

Superficial layering of eosinophils

Extracellular eosinophil granules

Epithelial desquamation

Basal zone hyperplasia

Rete peg elongation

Dilated intercellular spaces

Subepithelial fibrosis/sclerosis-lamina propria fibrosis

Mastocytosis and mast cell degranulation

$\mathrm{CD}^{+}{ }^{+}$lymphocytes and B cells 